\title{
Composition and mass size distribution of nitrated and oxygenated aromatic compounds in ambient particulate matter from southern and central Europe - implications for the origin
}

\author{
Zoran Kitanovski $^{1, \mathrm{a}}$, Pourya Shahpoury ${ }^{1,2}$, Constantini Samara ${ }^{3}$, Aristeidis Voliotis $^{3,4}$, and Gerhard Lammel ${ }^{1,5}$ \\ ${ }^{1}$ Multiphase Chemistry Department, Max Planck Institute for Chemistry, Mainz, Germany \\ ${ }^{2}$ Air Quality Processes Research Section, Environment and Climate Change Canada, Toronto, Canada \\ ${ }^{3}$ Environmental Pollution Control Laboratory, Department of Chemistry, Aristotle University of Thessaloniki, \\ Thessaloniki, Greece \\ ${ }^{4}$ Centre for Atmospheric Sciences, School of Earth and Environmental Sciences, University of Manchester, Manchester, UK \\ ${ }^{5}$ Research Centre for Toxic Compounds in the Environment, Masaryk University, Brno, Czech Republic \\ anow at: Lek Pharmaceuticals d.d., Ljubljana, Slovenia
}

Correspondence: Zoran Kitanovski (z.kitanovski@mpic.de) and Pourya Shahpoury (p.shahpoury@mpic.de)

Received: 25 July 2019 - Discussion started: 7 August 2019

Revised: 22 December 2019 - Accepted: 19 January 2020 - Published: 2 March 2020

\begin{abstract}
Nitro-monoaromatic hydrocarbons (NMAHs), such as nitrocatechols, nitrophenols and nitrosalicylic acids, are important constituents of atmospheric particulate matter (PM) water-soluble organic carbon (WSOC) and humic-like substances (HULIS). Nitrated and oxygenated derivatives of polycyclic aromatic hydrocarbons (NPAHs and OPAHs) are toxic and ubiquitous in the ambient air; due to their light absorption properties, together with NMAHs, they are part of aerosol brown carbon $(\mathrm{BrC})$. We investigated the winter concentrations of these substance classes in size-resolved PM from two urban sites in central and southern Europe, i.e. Mainz (MZ), Germany, and Thessaloniki (TK), Greece. The total concentration of 11 NMAHs $\left(\sum_{11}\right.$ NMAH concentrations) measured in $\mathrm{PM}_{10}$ and total $\mathrm{PM}$ were $0.51-8.38$ and $12.1-72.1 \mathrm{ng} \mathrm{m}^{-3}$ at the $\mathrm{MZ}$ and TK sites, respectively, whereas $\sum_{7}$ OPAHs were $47-1636$ and $858-4306 \mathrm{pg} \mathrm{m}^{-3}$, and $\sum_{8}$ NPAHs were $\leq 90$ and $76-578 \mathrm{pg} \mathrm{m}^{-3}$, respectively. NMAHs contributed $0.4 \%$ and $1.8 \%$ to the HULIS mass at MZ and TK, respectively. The mass size distributions of the individual substances generally peaked in the smallest or second smallest size fraction i.e. $<0.49$ or $0.49-0.95 \mu \mathrm{m}$. The mass median diameter (MMD) of NMAHs was 0.10 and $0.27 \mu \mathrm{m}$ at $\mathrm{MZ}$ and TK, respectively, while the MMDs of NPAHs and OPAHs were both $0.06 \mu \mathrm{m}$ at MZ and 0.12 and $0.10 \mu \mathrm{m}$ at TK. Correlation analysis between NMAHs,
\end{abstract}

NPAHs, and OPAHs from one side and WSOC, HULIS, sulfate, and potassium from the other suggested that fresh biomass burning (BB) and fossil fuel combustion emissions dominated at the TK site, while aged air masses were predominant at the $\mathrm{MZ}$ site.

\section{Introduction}

Atmospheric humic-like substances (HULIS) represent a complex mixture of aliphatic and aromatic compounds with multiple functional groups, such as hydroxyl, carbonyl, carboxyl, nitro, nitrooxy, and sulfate groups (Havers et al., 1998; Graber and Rudich, 2006; Hallquist et al., 2009; Claeys et al., 2012). They are a major constituent of aerosol water-soluble organic carbon (WSOC), contributing between $9 \%$ and $72 \%$ to WSOC mass (Decesari et al., 2000; Graber and Rudich, 2006; Lin et al., 2010; Zheng et al., 2013). The distribution of HULIS molecular weights (MWs) is unimodal and ranges between 100 and $500 \mathrm{Da}$, with most of the compounds grouping around $200 \mathrm{Da}$ (Graber and Rudich, 2006; Claeys et al., 2012; Song et al., 2018), unlike soil humic and fulvic acids with MW distributions extending well beyond 1000 Da. Due to the presence of light-absorbing polyconjugated and aromatic compounds (Duarte et al., 2005; Graber and Rudich, 
2006; Claeys et al., 2012; Zheng et al., 2013), HULIS are an important constituent of aerosol water-soluble brown carbon (BrC; Laskin et al., 2015, and references therein). The intense light absorption of HULIS in the ultraviolet, violet, and blue visible regions, between 200 and $500 \mathrm{~nm}$, can affect aerosol optical properties and atmospheric photochemical processes (Andreae and Gelencsér, 2006). Owing to the presence of highly polar polyfunctional material, HULIS have surface-active properties and can make aerosols act as cloud condensation nuclei $(\mathrm{CCN})$. In the aerosol aqueous phase, HULIS can increase the solubility of hydrophobic organic compounds and change the reactivity and solubility of metal aerosols, owing to metal-complexation properties (Graber and Rudich, 2006). Finally, due to the presence of redox-active moieties, HULIS can catalyse electron transfer reactions and formation of reactive oxygen species (ROS), which could pose oxidative stress in humans upon inhalation (Verma et al., 2015).

Biomass burning (BB) is considered as one of the main sources of HULIS in the atmosphere (Lin et al., 2010; Claeys et al., 2012; Pavlovic and Hopke, 2012; Zheng et al., 2013) and an important source of aerosol nitroaromatic compounds (Claeys et al., 2012; Song et al., 2018). Recent studies found that nitro-monoaromatic hydrocarbons (NMAHs), such as 4-nitrocatechol (4-NC; MW: 155 Da) and isomeric methylnitrocatechols (MNCs; MW: 169 Da), are abundant constituents of particulate matter (PM) HULIS, originating from BB (Claeys et al., 2012; Song et al., 2018).

NMAHs are emitted into the atmosphere by primary and secondary processes. 4-NC, MNCs, nitroguaiacols (NGs) and nitrosalicylic acids (NSAs) are predominantly formed by secondary oxidation of lignin thermal decomposition products (e.g. m-cresol, phenols, methoxyphenols, catechols, salicylic acid) in the gas and aqueous phases (Iinuma et al., 2010; Kelly et al., 2010; Kroflič et al., 2015; Frka et al., 2016; Teich et al., 2017; Finewax et al., 2018; Xie et al., 2017; Wang et al., 2019). Therefore, the yellow-coloured watersoluble 4-NC and MNCs have been proposed as suitable tracers for highly oxidized secondary BB aerosols (Iinuma et al., 2010; Kitanovski et al., 2012b; Kahnt et al., 2013; Caumo et al., 2016; Chow et al., 2016). In the past decade, the ambient PM nitrocatechols (NCs) have been measured in several studies worldwide, i.e. in Europe (Iinuma et al., 2010; Zhang et al., 2010; Kitanovski et al., 2012b; Kahnt et al., 2013; Mohr et al., 2013; Teich et al., 2014; Frka et al., 2016), South America (Claeys et al., 2012; Caumo et al., 2016), North America (al-Naiema and Stone, 2017), Asia (Chow et al., 2016; Li et al., 2016; Wang et al., 2019), and Australia (Iinuma et al., 2016). They represent a significant fraction of the PM organic carbon (OC), e.g. $0.8 \%$ in winter $\mathrm{PM}_{10}$ collected at an urban background location in Slovenia (range 0.4\%-1.3\%; Kitanovski et al., 2012b), $0.75 \%$ in winter $\mathrm{PM}_{10}$ collected at rural site in Belgium (Kahnt et al., 2013), and $\approx 0.3 \%$ in $\mathrm{PM}_{10}$ collected in Brazil during the BB season (Caumo et al., 2016). Nitrosalicylic acids (2- hydroxy-nitrobenzoic acids) have been reported in PM samples collected at rural (van Pinxteren and Herrmann, 2007; van Pinxteren et al., 2012; Teich et al., 2017; Wang et al., 2018), urban (Kitanovski et al., 2012a, b; Teich et al., 2017; Wang et al., 2018) and remote (Wang et al., 2018) sites. Similar to NCs, they are mainly associated with secondary BB aerosols (Kitanovski et al., 2012b; Teich at el., 2017; Wang et al., 2018). Nitrophenols (NPs), compounds structurally related to NCs, are emitted from primary sources (e.g. traffic, coal, and wood combustion, industry, and the agricultural use of pesticides), which predominate their secondary formation in urban areas (Harrison et al., 2005; Cecinato et al., 2005; Hoffmann et al., 2007; Iinuma et al., 2007; Zhang et al., 2010; Ganranoo et al., 2010; Özel et al., 2011; Mohr et al., 2013; Kitanovski et al., 2012a, b; Inomata et al., 2015; Teich et al., 2017; Wang et al., 2018; Lu et al., 2019a, b).

Polycyclic aromatic hydrocarbons (PAHs) and their nitrated and oxygenated derivatives (NPAHs and OPAHs), as well as hydroxy derivatives (OH-PAHs), are ubiquitous in the atmosphere (Walgraeve et al., 2010; Lammel, 2015; Bandowe and Meusel, 2017; Shahpoury et al., 2018). They are primarily emitted from the incomplete combustion of fossil fuels (Zielinska et al., 2004; Karavalakis et al., 2010; Pham et al., 2013; Inomata et al., 2015) and wood, coal, and biomass burning (Ding et al., 2012; Shen et al., 2012, 2013a, b; Huang et al., 2014; Vicente et al., 2016). The PAH derivatives are secondarily formed by the reaction of parent PAHs with atmospheric oxidants such as $\mathrm{OH}, \mathrm{NO}_{x}$ and $\mathrm{O}_{3}$. Some NPAHs have distinct sources; for instance, 3nitrofluoranthene (3-NFLT) and 1-nitropyrene (1-NPYR) are specifically associated with combustion sources, whereas 2nitrofluoranthene (2-NFLT) and 2-nitropyrene (2-NPYR) are produced through the oxidation of their parent species in the atmosphere (Bandowe and Meusel, 2017). Similarly, OPAHs benzanthrone (OBAT), benz(a)fluorenone (BaOFLN), and benz(b)fluorenone (BbOFLN) have been associated with primary sources, whereas 9,10 -anthraquinone $\left(9,10-\mathrm{O}_{2} \mathrm{ANT}\right)$, 1,2-benzanthraquinone (1,2- $\left.\mathrm{O}_{2} \mathrm{BAA}\right)$, and 9-fluorenone (9OFLN) have been attributed to both source types (Kojima et al., 2010; Souza et al., 2014; Lin et al., 2015; Zhuo et al., 2017). The primary sources dominate in wintertime with residential heating surpassing traffic emission (Lin et al., 2015). It is anticipated that functionalized two- and three-ring PAHs (e.g. two- and three-ring OPAHs) would exhibit the highest hydrophilicity among their analogues and could also be part of PM HULIS (Vione et al., 2014; Fan et al., 2016; Haynes et al., 2019). The water-soluble OPAHs, in particular quinones, were suggested to contribute to light absorption properties of brown carbon (Laskin et al., 2015; Haynes et al., 2019). Moreover, the ROS activity of HULIS from $\mathrm{PM}_{2.5}$ was associated with OPAHs, i.e. quinones and hydroxy-quinones (Verma et al., 2015). It has been shown in controlled experiments that the chemical ageing of PM from various origins would increase its ROS activity, and this effect is enhanced in the presence of $\mathrm{O}_{3}$ ( $\mathrm{Li}$ et al., 2009; McWhinney et al., 2011; 
Stevanovic et al., 2013; Verma et al., 2015; Antiñolo et al., 2015). This process has been attributed to the oxidation of PAHs and formation of water-soluble derivatives.

NMAHs, PAHs, NPAHs and OPAHs significantly contribute to the aerosol $\mathrm{BrC}$ due to their light absorption capacity in the ultraviolet (UV) and visible range (Mohr et al., 2013; Samburova et al., 2016; Teich et al., 2017; Xie et al., 2017; Huang et al., 2018). Determining the size-resolved mass distribution of the PM molecular tracers is important for assessing the particle emission sources, atmospheric transport, and health effects (Neusüss et al., 2000). In particular, there is limited knowledge about the size-resolved characteristics of NMAHs, NPAHs and OPAHs and their relation to atmospheric HULIS (Claeys et al., 2012; Song et al., 2018). Therefore, the aim of the present work is to fill this gap by studying the size-resolved PM from polluted urban air at two locations in central and southern Europe, i.e. Mainz (MZ), Germany, and Thessaloniki (TK), Greece, and to apply these data to determine the possible emission sources. These sites were selected to reflect the dominant emission sources in the study areas - while TK is a biomass burning hotspot in southeastern Europe (Saffari et al., 2013; Velali et al., 2019), MZ in central Europe is dominated by traffic emission and long-range transport (Winkler and Junge, 1972; Wesp et al., 2000; Dusek et al., 2006).

\section{Experimental}

\subsection{Collection of samples}

Size-segregated wintertime (season of 2015-2016) PM samples were collected at MZ and TK. In this period, the emissions influencing the sample sites are very different, and, in terms of temperature changes and synoptically, the sampling period is characterized by southwesterly advection with moderate winds at MZ and weak southerly or northeasterly winds at TK (Saffari et al., 2013; Voliotis et al., 2017). At MZ $(\approx 200000$ inhabitants), the sampling was done on the rooftop (12 m a.g.l.) of the Max Planck Institute for Chemistry, in a suburb about $2 \mathrm{~km}$ away from the city centre. This area was influenced by air masses which consisted of urban and rural continental boundary layer air. At TK (> 1000000 inhabitants), the sampling was performed on a rooftop ( $25 \mathrm{~m}$ a.g.l.) at the Aristotle University campus, in a residential area substantially influenced by wood burning for domestic purposes in winter (Voliotis et al., 2017). For each sample set, the air was collected for the duration of 70 and $48 \mathrm{~h}$ at MZ and TK, respectively.

All PM samples were collected using a five-stage highvolume cascade impactor with effective cutoff diameters: $0.49,0.95,1.5,3$, and $7.2 \mu \mathrm{m}$ of aerodynamic particle size, $D_{\mathrm{p}}$, and a backup filter collecting particles $<0.49 \mu \mathrm{m}$ (Table 1). The sampling in MZ was done using a high-volume air sampler Baghirra HV-100P (Baghirra, Prague, Czech Re- public) equipped with a multi-stage cascade impactor (Tisch Environmental Inc., Cleves, Ohio, USA; series 230, model 235) and a $\mathrm{PM}_{10}$ head. The PM was sampled on slotted quartz fibre filters (QFFs, TE-230-QZ, Tisch Environmental Inc.; $14.3 \times 13.7 \mathrm{~cm}$ ) and a QFF backup filter (Whatman; $20.3 \times 25.4 \mathrm{~cm}$ ). Four sets of samples were collected at MZ between November and December 2015, each over the period of $70 \mathrm{~h}$ (flow rate: $60 \mathrm{~m}^{3} \mathrm{~h}^{-1}$; Table 1). The impactor used in TK was a Sierra Instruments model 235; the PM samples were collected on QFFs (Tisch Environmental Inc.; TE-230-QZ; slotted $5.7 \times 5.7 \mathrm{~cm}$ ) and on QFF backup filters (Pall Corporation, Port Washington, New York, USA; 2500 QAT-UP), without a $\mathrm{PM}_{10}$ head, as described in Voliotis et al. (2017). Five sample sets were collected at TK between January and March 2016 (Table 1).

\subsection{Sample preparation and analytical methods}

\subsubsection{Chemical analysis of NMAHs}

Extraction of the filter samples for NMAH analysis was done using a validated procedure (Kitanovski et al., 2012b) with small modifications. Briefly, a $1.5 \mathrm{~cm}^{2}$ section of the filter was spiked with 2,4,6-trinitrophenol and 4-nitrophenol$\mathrm{d}_{4}$ (internal standards - IS; spiked mass: $100 \mathrm{ng}$; Sect. S1) and subsequently extracted three times $(5 \mathrm{~min}$ each) with a $10 \mathrm{~mL}$ methanolic solution of ethylenediaminetetraacetic acid (EDTA; $3.4 \mathrm{nmol} \mathrm{mL}^{-1}$ ) in an ultrasonic bath. The combined extracts were concentrated to $0.5 \mathrm{~mL}$ using a TurboVap II (bath temperature: $40^{\circ} \mathrm{C}$; nitrogen gas pressure: $15 \mathrm{psi}$; Biotage, Uppsala, Sweden). The concentrated extract was filtered through a $0.2 \mu \mathrm{m}$ PTFE syringe filter $(4 \mathrm{~mm}$; Whatman, GE Healthcare, Little Chalfont, UK) into a $2 \mathrm{~mL}$ vial and was evaporated to near dryness under the gentle stream of nitrogen (99.999\%; Westfalen AG, Münster, Germany). Finally, the extract was dissolved in a methanol / water mixture (3/7, $v / v$ ) containing a $5 \mathrm{mM}$ ammonium formate buffer with a $\mathrm{pH}$ of 3 and $400 \mu \mathrm{M}$ of EDTA for liquid chromatography/mass spectrometry (LC/MS) analysis.

The NMAHs were determined using an Agilent 1200 Series high-performance liquid chromatography (HPLC) system (Agilent Technologies, Waldbronn, Germany) coupled to an Agilent 6130B Series single quadrupole mass spectrometer equipped with an electrospray ionization (ESI) source. High-purity nitrogen was used as a nebulizer and drying gas. The separation of the targeted analytes was done on an Atlantis T3 column $(150 \mathrm{~mm} \times 2.1 \mathrm{~mm}$ ID; $3 \mu \mathrm{m}$ particle size; Waters, Milford, Massachusetts, USA) connected to an Atlantis T3 VanGuard pre-column $(5 \mathrm{~mm} \times 2.1 \mathrm{~mm} \mathrm{ID}$; $3 \mu \mathrm{m}$ particle size; Waters), using isocratic elution with a mobile phase consisting of a methanol / tetrahydrofuran / water $(30 / 15 / 55, v / v / v)$ mixture containing $5 \mathrm{mM}$ ammonium formate buffer with a pH of 3 (Sect. S1 in the Supplement). The mobile-phase flow rate, column temperature and injection volume were $0.2 \mathrm{~mL} \mathrm{~min}^{-1}, 30^{\circ} \mathrm{C}$ and $10 \mu \mathrm{L}$, respec- 
Table 1. Sampling details.

\begin{tabular}{lrlr}
\hline & Cutoff diameters $(\mu \mathrm{m})$ & Sampling date & Sample volume $\left(\mathrm{m}^{3}\right)$ \\
\hline Mainz & $10-7.2$ & & \\
$49.99^{\circ} \mathrm{N}$ & $7.2-3$ & $17-20$ November 2015 & 3402 \\
$8.23^{\circ} \mathrm{E}$ & $3-1.5$ & $26-29$ November 2015 & 4124 \\
& $1.5-0.95$ & $1-4$ December 2015 & 4088 \\
& $0.95-0.49$ & $4-7$ December 2015 & 4197 \\
& $<0.49$ & & 3228 \\
\hline Thessaloniki & & 27-29 January 2016 & 3228 \\
$40.63^{\circ} \mathrm{N}$ & $10-3^{*}$ & 8-10 February 2016 & 3228 \\
$22.96^{\circ} \mathrm{E}$ & $3-0.95^{*}$ & $16-18$ February 2016 & 3172 \\
& $0.95-0.49$ & $22-24$ February 2016 & 3175 \\
\hline
\end{tabular}

* Pooled from two impactor stages.

tively (Kitanovski et al., 2012b). The detection and quantification of NMAHs was done in single-ion monitoring and negative ESI mode (Table 2). The optimized ESI-MS parameters were as follows: $-1000 \mathrm{~V}$ for the ESI capillary voltage, $30 \mathrm{psi}$ for the nebulizer pressure, and $12 \mathrm{~L} \mathrm{~min}^{-1}$ and $340^{\circ} \mathrm{C}$ for the drying gas flow and temperature, respectively. Due to the lack of a reference standard for 3-methyl-4-nitrocatechol (3-M-4-NC), its concentrations were calculated based on the calibration curve of 4-M-5-NC. This is justified based on the structural similarity of the two substances and therefore similar ionization efficiency under ESI-MS conditions. LC/MSD ChemStation (Agilent Technologies) was used for data acquisition and analysis. The mean recovery of target NMAHs at $100 \mathrm{pg} \mu \mathrm{L}^{-1}$ was $91 \pm 3 \%$.

\subsubsection{Chemical analysis of NPAHs and OPAHs}

NPAHs and OPAHs were extracted from PM samples following a QuEChERS (quick, easy, cheap, effective, rugged, and safe) method with slight modifications (Albinet et al., 2014; Shahpoury et al., 2018). Briefly, two strips of each filter paper were placed inside a glass centrifuge tube (Duran, Schott, Mainz, Germany) and spiked with a mixture of internal standards containing $60 \mathrm{ng}$ of 1-nitronaphthalene- $\mathrm{d}_{7}, 2$-nitrofluorene- $\mathrm{d}_{9}$, 9-nitroanthracene-d , 3-nitrofluoranthene-d9, 1-nitropyrene$\mathrm{d}_{9}$, 6-nitrochrysene- $\mathrm{d}_{11}, 9,10$-anthraquinone- $\mathrm{d}_{8}$, and 9fluorenone- $\mathrm{d}_{8}$ each. A total of $7 \mathrm{~mL}$ of dichloromethane (DCM) was then added to each tube; the tubes were capped, and the samples were extracted by vortexing for $1.5 \mathrm{~min}$. The extracts were passed through a glass funnel plugged with deactivated glass wool and concentrated to $0.5 \mathrm{~mL}$ using a TurboVap II. The concentrated extracts were loaded on preconditioned $\mathrm{SiO}_{2}$ solid-phase extraction cartridges $(500 \mathrm{mg}$; Macherey-Nagel, Weilmünster, Germany), and the target analytes were eluted with $9 \mathrm{~mL}$ of $65: 35 n$-hexane-DCM.
The purified extracts containing the analytes were concentrated to $0.5 \mathrm{~mL}$, and the solvent was exchanged by adding $5 \mathrm{~mL}$ of ethyl acetate, concentrating the solution to $0.5 \mathrm{~mL}$, and the process was repeated three times. The sample volumes were adjusted to $0.3 \mathrm{~mL}$ and transferred to $2 \mathrm{~mL}$ vials containing $0.4 \mathrm{~mL}$ glass inserts. All solvents used for NPAH and OPAH analysis were high-purity (Suprasolv, GC-MS grade; Merck, Darmstadt, Germany). All glassware used for analysis was pre-washed with lab-grade detergent, tap water and deionized water and baked at $310^{\circ} \mathrm{C}$ for $12 \mathrm{~h}$.

The samples were analysed using a Trace 1310 gas chromatograph (GC; Thermo Scientific, Waltham, Massachusetts, USA) interfaced to a TSQ8000 Evo triple quadrupole mass selective detector (MS/MS; Thermo Scientific). The analysis was performed in negative chemical ionization with methane used as an ionization gas $\left(1.5 \mathrm{~mL} \mathrm{~min}^{-1}\right.$ flow rate; $>99.99 \%$; Messer, Bad Soden, Germany). The analytes were separated on a $30 \mathrm{~m}$ DB5ms capillary column $(0.25 \mathrm{~mm}$ ID; $0.25 \mu \mathrm{m}$ film thickness; J\&W, Santa Clara, California, USA) with helium (99.99\%; Westfalen AG, Münster, Germany) as a carrier gas at a $1 \mathrm{~mL} \mathrm{~min}^{-1}$ flow rate. The GC inlet temperature was set to $250^{\circ} \mathrm{C}$ and operated in the pulsed splitless mode (30 psi pulsed pressure for $1.5 \mathrm{~min}$; splitless time of $1.8 \mathrm{~min}$ ). The $\mathrm{GC}$ oven temperature was held at $60^{\circ} \mathrm{C}$ for $2 \mathrm{~min}$ at the start of the analysis, and it was then increased to $180^{\circ} \mathrm{C}$ at $15^{\circ} \mathrm{C} \mathrm{min}-1$ and to $280^{\circ} \mathrm{C}$ at $5{ }^{\circ} \mathrm{C} \mathrm{min}^{-1}$, followed by a final hold time of $15 \mathrm{~min}$. The MS transfer line and ion source temperature were set to 290 and $230^{\circ} \mathrm{C}$, respectively. Emission current and electron energy were set to $100 \mu \mathrm{A}$ and $-70 \mathrm{eV}$, respectively. The target analytes were detected in the selected-ion monitoring mode, identified using their retention times and quantification ions (Table 2). The quantification was performed using the internal calibration method and 11-point calibration curves ranging from 0.25 to $1000 \mathrm{pg}_{\mu} \mathrm{L}^{-1}$. Trace Finder (Thermo Scientific, Waltham, Massachusetts, USA) was used for chromato- 
Table 2. Analytes targeted in this study.

\begin{tabular}{|c|c|c|}
\hline Analyte & Abbreviation & Q1 \\
\hline 3-Nitrosalicylic acid & 3-NSA & 182 \\
\hline 5-Nitrosalicylic acid & 5-NSA & 182 \\
\hline 4-Nitrocatechol & 4-NC & 154 \\
\hline 4-Nitroguaiacol & $4-\mathrm{NG}$ & 168 \\
\hline 4-Methyl-5-nitrocatechol & 4-M-5-NC & 168 \\
\hline 4-Nitrophenol & $4-\mathrm{NP}$ & 138 \\
\hline 2,4-Dinitrophenol & 2,4-DNP & 183 \\
\hline 3-Methyl-4-nitrophenol & 3-M-4-NP & 152 \\
\hline 3-Methyl-5-nitrocatechol & 3-M-5-NC & 168 \\
\hline 3-Methyl-4-nitrocatechol & 3-M-4-NC & 168 \\
\hline 2-Methyl-4-nitrophenol & 2-M-4-NP & 152 \\
\hline $\begin{array}{l}\text { 2-Methyl-3,5-dinitrophenol } \\
\text { (Dinitro-ortho-cresol) }\end{array}$ & DNOC & 197 \\
\hline 1-Nitronaphthalene & 1-NNAP & 173.1 \\
\hline 2-Nitronaphthalene & 2-NNAP & 173.1 \\
\hline 5-Nitroacenaphthene & 5-NACE & 199.1 \\
\hline 2-Nitrofluorene & 2-NFLN & 211.1 \\
\hline 9-Nitroanthracene & 9-NANT & 223.1 \\
\hline 9-Nitrophenanthrene & 9-NPHE & 223.1 \\
\hline 3-Nitrophenanthrene & 3-NPHE & 223.1 \\
\hline 2-Nitrofluoranthene & 2-NFLT & 247.1 \\
\hline 3-Nitrofluoranthene & 3-NFLT & 247.1 \\
\hline 1-Nitropyrene & 1-NPYR & 247.1 \\
\hline 2-Nitropyrene & 2-NPYR & 247.1 \\
\hline 7-Nitrobenz(a)anthracene & 7-NBAA & 273.1 \\
\hline 6-Nitrochrysene & 6-NCHR & 273.1 \\
\hline 1,3-Dinitropyrene & $1,3-\mathrm{N}_{2} \mathrm{PYR}$ & 292.1 \\
\hline 1,6-Dinitropyrene & $1,6-\mathrm{N}_{2} \mathrm{PYR}$ & 292.1 \\
\hline 1,8-Dinitropyrene & $1,8-\mathrm{N}_{2} \mathrm{PYR}$ & 292.1 \\
\hline 6-Nitrobenz(a)pyrene & 6-NBAP & 297.1 \\
\hline 1,4-Naphthoquinone & $1,4-\mathrm{O}_{2} \mathrm{NAP}$ & 158.1 \\
\hline 9-Fluorenone & 9-OFLN & 180.1 \\
\hline 9,10-Anthraquinone & $9,10-\mathrm{O}_{2} \mathrm{ANT}$ & 208.1 \\
\hline 2-Nitro-9-fluorenone & 2-N-9-OFLN & 225.1 \\
\hline Benz(a)fluorenone & $\mathrm{BaOFLN}$ & 230.1 \\
\hline Benz(b)fluorenone & BbOFLN & 230.1 \\
\hline Benzanthrone & OBAT & 230.1 \\
\hline 1,2-Benzanthraquinone & $1,2-\mathrm{O}_{2} \mathrm{BAA}$ & 258.1 \\
\hline
\end{tabular}

graphic data acquisition and analysis. The mean recoveries of target NPAHs and OPAHs at $200 \mathrm{pg} \mu \mathrm{L}^{-1}$ were $73 \pm 15 \%$ and $72 \pm 18 \%$, respectively.

\subsubsection{Quality control and data analysis}

Field blanks $(n=3)$ were prepared during sample collection by mounting the pre-baked filters on the sampler without switching it on. These filters were subsequently retrieved and processed along with the rest of the samples. Limits of quantification (LOQs) for analytes were calculated as the mean concentration of each analyte in blanks +3 stan- dard deviations. When analyte concentrations in the samples exceeded the LOQ, mean blank concentrations were subtracted from those in the corresponding samples. Microsoft Office Excel 2013 (Microsoft Corp., Redmond, Washington, USA) and OriginPro 9.0 (OriginLab Corp., Northampton, Massachusetts, USA) were used for statistical analysis and data visualization. Mass size distributions (MSDs) of NMAHs, NPAHs and OPAHs were additionally characterized by the mass median diameter (MMD), defined as $\log \mathrm{MMD}=\Sigma\left(c_{i} \log D_{i}\right) / \Sigma c_{i}$, with $c_{i}$ and $D_{i}$ being the concentration $\left(\mathrm{ng} \mathrm{m}^{-3}\right)$ and geometric mean diameter, respectively, of six impactor stages. For consistency across the samples, $0.001 \mu \mathrm{m}$ was adopted as the lower cutoff of the lowermost stage (backup filter), and $10 \mu \mathrm{m}$ was the upper cutoff of the uppermost stage, even in the absence of a $\mathrm{PM}_{10}$ inlet in the case of TK samples. Although this may introduce a small underestimation of MMDs for TK samples, during the sampling at TK, wind velocities did not favour resuspension of large particles and sea spray; hence, we expect that the contribution of PM $>10 \mu \mathrm{m}$ would be negligible. The concentrations of ions, organic acids, HULIS, and HULIS-C in the samples used in this study can be found in a companion paper (Voliotis et al., 2017).

\section{Results and discussion}

\subsection{Sources of NMAHs, NPAHs and OPAHs at Thessaloniki and Mainz}

\subsubsection{Concentrations and sources of NMAHs}

From the 11 targeted NMAHs, 8 were consistently detected in size-segregated PM from MZ and TK. 4-NG and DNOC were not detected in MZ samples, while they were sporadically detected in the coarse PM $(>3 \mu \mathrm{m})$ from TK. 2,4DNP was detected more frequently in TK (three sample sets) than in MZ samples (one sample set). The concentrations of NMAHs associated to $\mathrm{PM}_{10}$ (MZ) and total PM (TK) are given in Table S3 in the Supplement. The $\sum_{11} \mathrm{NMAH}$ concentrations in PM from MZ and TK were 0.51-8.38 and $12.1-72.1 \mathrm{ng} \mathrm{m}^{-3}$, respectively. In all sample sets, 4-NC was the most abundant NMAH with concentrations ranging within $0.05-3.90 \mathrm{ng} \mathrm{m}^{-3}$ (mean: $2.46 \mathrm{ng} \mathrm{m}^{-3}$; Table S3) in MZ samples and concentrations that were 10 times higher in TK samples $\left(5.89-36.33 \mathrm{ng} \mathrm{m}^{-3}\right.$; mean: $22.11 \mathrm{ng} \mathrm{m}^{-3}$; Table S3). 4-NP was the second-most abundant NMAH in $\mathrm{MZ}$ with concentrations between 0.24 and $1.27 \mathrm{ng} \mathrm{m}^{-3}$ (mean: $0.83 \mathrm{ng} \mathrm{m}^{-3}$; Table S3), while 4-M-5-NC was the second-most abundant NMAH in TK samples (2.54 $16.05 \mathrm{ng} \mathrm{m}^{-3}$; mean: $9.79 \mathrm{ng} \mathrm{m}^{-3}$; Table S3). In general, the concentration trends of NMAHs were 4-NC $>$ MNCs $>4$ $\mathrm{NP}>\mathrm{NPs}>\mathrm{NSAs}>\mathrm{DNP}$ (dinitrophenols) for MZ samples and 4-NC $>$ MNCs $>4-\mathrm{NP}>\mathrm{NSAs}>\mathrm{NPs}>\mathrm{DNP}$ for TK samples. These trends are in good agreement with other stud- 
ies, where 4-NC, MNCs, and 4-NP were the most abundant NMAHs (Kitanovski et al., 2012b; Chow et al., 2016). However, we previously found different concentration trends in snow-scavenged atmospheric particles collected in MZ, where 4-NC and MNCs were the second-most abundant NMAH species following NPs (Shahpoury et al., 2018). $\sum \mathrm{NMAH}$ winter concentrations at TK were higher than those found in winter $\mathrm{PM}_{2.5}$ and $\mathrm{PM}_{10}$ from Hong Kong (Chow et al., 2016) and rural Belgium (Kahnt et al., 2013), respectively, but they were lower than NMAH concentrations in winter $\mathrm{PM}_{10}$ samples from Ljubljana, Slovenia (Kitanovski et al., 2012b), and Shanghai, China (Li et al., 2016). The concentrations of individual NMAHs in winter $\mathrm{PM}_{10}$ from MZ were among the lowest values reported so far (Iinuma et al., 2010; Kitanovski et al., 2012b; Kahnt et al., 2013; Mohr et al., 2013; Chow et al., 2016; Li et al., 2016; Teich et al., 2017; Wang et al., 2019).

In Table S3, one can easily notice the consistently higher $(\approx 10$ times) total PM concentrations of 4-NC, MNCs, and NSAs in TK samples compared to those found in $\mathrm{PM}_{10}$ samples from MZ. Smaller concentration discrepancies among the sites were observed for 4-NP and methyl-nitrophenols (MNPs; up to 3 times higher concentrations in TK samples). Since 4-NC, MNCs, and NSAs are considered as suitable tracers for secondary BB aerosols (Iinuma et al., 2010; Kitanovski et al., 2012b; Kahnt et al., 2013; Caumo et al., 2016; Chow et al., 2016; Teich et al., 2017), this suggests that the air masses over TK during sample collection were most likely influenced by BB emissions. To test this hypothesis, a correlation analysis was done for NMAHs. Initially, we did the correlation analysis on $\mathrm{PM}_{10}(\mathrm{MZ})$ and total PM (TK) samples (Tables S4 and S7). Although the correlation analysis was performed using a limited number of sample sets per location (five for TK and four for MZ), it showed several interesting features. Based on these results, we propose the most probable sources for NMAHs at both sampling sites. Overall, except for NPs in TK samples, high correlations were observed within the NMAH sub-groups (NSAs, NCs, and NPs; $R_{\text {adj }}^{2}>0.8$; Tables $\mathrm{S} 4$ and S7). In TK samples, 5-NSA was highly correlated $\left(R_{\text {adj }}^{2} 0.81-0.83\right)$ with 4-NP and potassium cation $\left(\mathrm{K}^{+}\right)$, but it showed insignificant correlations with 4-NC, MNCs, and nitrate (Table S4). 3-NSA showed significant $(p<0.05)$ correlation with $\mathrm{K}^{+}$, but it had a moderate correlation with 4-NP, whereas 4-NP was highly correlated with $\mathrm{K}^{+}$and nitrate $\left(R_{\text {adj }}^{2} 0.94\right.$ and 0.81 , respectively). Secondly, 4-NC and 4-M-5-NC showed low correlations with $\mathrm{K}^{+}$and nitrate, but it was highly correlated with $3-\mathrm{M}-4-\mathrm{NP}\left(R_{\text {adj }}^{2} 0.74\right.$ and 0.78 , respectively). Finally, the high correlations between $\mathrm{K}^{+}$and WSOC or HULIS $\left(R_{\text {adj }}^{2} \sim\right.$ 0.9 ) suggest a strong influence of primary BB emissions on WSOC concentrations at TK. Based on the correlation analysis, our results from TK indicate distinct emission sources for NSAs and 4-NP on the one hand and for 4-NC and MNCs on the other hand. NSAs and 4-NP most likely had the same emission source, i.e. BB (correlate with $\mathrm{K}^{+} ; 0.81<R_{\mathrm{adj}}^{2}<$ $0.94)$. Additionally, they also showed moderate-to-high correlations with WSOC and HULIS $\left(0.59<R_{\text {adj }}^{2}<0.78\right.$; Table S4). Within specific PM size ranges, $\mathrm{PM}_{0.97}$ (Table S5) and $\mathrm{PM}_{3-0.97}$ (Table S6), we found significant correlations $(p<0.05)$ between NSAs and $\mathrm{K}^{+}$, WSOC, HULIS, and 4$\mathrm{NP}$ in the sub-micrometre particles $\left(\mathrm{PM}_{0.97}\right)$. This could indicate either fresh emissions of NSAs during BB (for instance, 3-NSA could also be primarily emitted by BB; Wang et al., 2017) or secondary formation (nitration of salicylic acid, primarily emitted by BB; Iinuma et al., 2007) and subsequent gas-to-particle conversion. 4-NP correlated significantly with $\mathrm{K}^{+}$, WSOC, and HULIS in $\mathrm{PM}_{0.97}$ and $\mathrm{PM}_{3-0.97}$ but also with NSAs and sulfates in these size ranges, respectively. These results imply that BB is a predominant source of 4-NP in sub-micrometre particles, while additional anthropogenic sources (e.g. coal burning and industry) might also contribute to its concentrations in $\mathrm{PM}_{3-0.97}$ (high correlation with sulfate, Table S6; Lu et al., 2019a). In contrast, low correlations of 4-NC and MNCs with $\mathrm{K}^{+}$, WSOC and HULIS (Tables S5 and S6) suggest that BB might not be a significant emission source for NCs and that their possible source could be fossil fuel combustion (e.g. gas-phase nitration of NC precursors emitted by coal combustion; Kourtchev et al., 2014; Xie et al., 2017; Finewax et al., 2018; Wang et al., 2019; Lu et al., 2019a). Significant correlations of 3M-4-NP with 4-NC, 4-M-5-NC, and 3-M-5-NC were observed ( $R_{\text {adj }}^{2} \geq 0.71, p<0.05$; Table S5), in contrast to the insignificant correlations with 4-NP. MNP isomers (2-M-4NP and 3-M-4-NP) in $\mathrm{PM}_{0.97}$ and $\mathrm{PM}_{3-0.97}$ showed strong inter-correlations $\left(0.75 \leq R_{\text {adj }}^{2} \leq 0.92\right.$; Tables S5 and S6) but low correlations with $\mathrm{K}^{+}$, WSOC, and HULIS. This suggests that, similar to 4-NC and MNCs, MNPs' predominating source at TK was fossil fuel combustion (Noguchi et al., 2007; Lu et al., 2019a). Regardless, fresh BB emission remains a major contributor to PM WSOC at TK, as observed by the significant correlations of WSOC and HULIS with $\mathrm{K}^{+}$ $\left(R_{\text {adj }}^{2}=0.9\right.$; Tables S4 and S5). In conclusion, the emission profile and correlation analysis for NMAHs at TK suggest a complex interplay of different emission sources, particularly dominated by fresh BB and fossil fuel combustion emissions.

Correlation analysis for NMAHs in MZ samples presents a different picture (Table S7). Significant correlations ( $p<$ 0.05 ) were observed among different NMAH compound groups (i.e. NSAs, NCs, and NPs), with a majority of $R_{\text {adj }}^{2}$ being higher than 0.8 . In our previous work, high correlations $\left(R_{\text {adj }}^{2}>0.8\right)$ between NSAs and 4-NC or MNCs were also observed, which indicated the presence of BB secondary organic aerosol (SOA) (Kitanovski et al., 2012b). The correlations between $\mathrm{K}^{+}$and NSAs, 4-NC, and MNCs in $\mathrm{PM}_{0.95}$ were moderate to high $\left(0.4<R_{\mathrm{adj}}^{2}<0.8\right.$; Table S8), inferring that $\mathrm{BB}$ could have contributed to the formation of these species in the sub-micrometre particles. In the same PM size range, nitrate showed moderate-to-high correla- 
tions $\left(0.5 \leq R_{\text {adj }}^{2}<0.9\right)$ with NSAs, 4-NP, MNPs, 4-NC, and MNCs (Table S8), which are much higher than the corresponding ones in $\mathrm{PM}_{0.97}$ samples from TK (Table S5). In $\mathrm{PM}_{3-0.95}$, HULIS showed significant correlations with $\mathrm{K}^{+}$ $\left(R_{\mathrm{adj}}^{2}=0.99\right)$ and all NMAH species $\left(0.66<R_{\mathrm{adj}}^{2}<0.98\right.$; Table S9), except for 2,4-DNP, suggesting that NMAHs and PM HULIS had similar sources (i.e. BB). The significant correlations of 4-NC and MNCs with 4-NP and MNPs in $\mathrm{PM}_{0.95}$ and $\mathrm{PM}_{3-0.95}$ suggest similar sources for NCs and NPs over MZ. Moreover, high correlations of 4-NC and MNC with $\mathrm{K}^{+}$ in $\mathrm{PM}_{0.95}$ indicate that $\mathrm{BB}$ was a significant emission source over MZ (Chow et al., 2016; Voliotis et al., 2017; Wang et al., 2018), whereas their high correlations with sulfate in $\mathrm{PM}_{3-0.95}\left(0.66<R_{\text {adj }}^{2}<1.00\right.$; Table S9) could infer possible anthropogenic emissions, i.e. coal combustion (Lu et al., 2019a).

\subsubsection{Concentrations and sources of NPAHs and OPAHs}

NPAHs and OPAHs were studied in size-resolved PM at both the MZ and TK sites. At both sites, particle-phase OPAHs were detected more frequently than NPAHs: seven out of eight OPAHs targeted for analysis were detected in nearly all MZ and TK samples (Table S3; Figs. S3 and S4 in the Supplement). In contrast, only 8 out of 17 targeted NPAHs were found in the PM samples, of which only 1-nitronaphthalene (1-NNAP), 9-nitroanthracene (9NANT), 2-NFLT, and 7-nitrobenz(a)anthracene (7-NBAA) were detected in both MZ and TK samples. Interestingly, 3nitrophenanthrene (3-NPHE), 3-NFLT, and 1- and 2-NPYR were only found in TK samples. This was not due to differences in individual LOQs between the two sites (see Table S2). The mean concentrations of NPAHs in PM were dominated by 9-NANT followed by 2-NFLT and 7-NBAA at both sites (Figs. 1 and 2, Table S3), with concentrations reaching to 225,154 , and $71 \mathrm{pg} \mathrm{m}^{-3}$, respectively. This pattern closely resembles those previously reported for PM from several locations in central Europe (Tomaz et al., 2016, and references therein), including NPAHs found in snowscavenged atmospheric particles from the MZ sample site (Shahpoury et al., 2018). As for OPAHs, the mean analyte concentrations in PM were dominated by OBAT, followed closely by BbOFLN, BaOFLN, 9,10- ${ }_{2}$ ANT, and 1,2$\mathrm{O}_{2}$ BAA. The latter two quinones could be of high importance due to their redox activity and their potential to catalyse the formation of reactive oxygen species within the human respiratory system (Ayres et al., 2008; Bates et al., 2019). The two substances were found to dominate two out of four MZ samples with concentrations up to 221 and $137 \mathrm{pg} \mathrm{m}^{-3}$, respectively. These concentrations were higher at the TK site and reached 354 and $514 \mathrm{pg} \mathrm{m}^{-3}$, respectively.
Overall, all NPAHs and OPAHs showed considerably higher concentrations in TK than in MZ samples. $\sum N P A H$ concentrations in $\mathrm{PM}_{10}$ from $\mathrm{MZ}$ and in total PM from TK were $<$ LOQ-90 and $76-578 \mathrm{pg} \mathrm{m}^{-3}$, respectively, whereas $\sum$ OPAHs demonstrated much higher levels ranging from 47 to 1636 and from 858 to $4306 \mathrm{pg} \mathrm{m}^{-3}$, respectively. The sum of three quinones, 1,4-naphthoquinone (1,4- $\left.{ }_{2} \mathrm{NAP}\right), 9,10-$ $\mathrm{O}_{2}$ ANT, and 1,2- $\mathrm{O}_{2}$ BAA, were $30-363$ and $428-873 \mathrm{pg} \mathrm{m}^{-3}$ at these sites, respectively. The levels of particle-phase NPAHs found in MZ fall in the lower end of the range (50-500 $\mathrm{pg} \mathrm{m}^{-3}$ ) observed for various types of sites in Europe (Tomaz et al., 2016, and references therein). The levels at TK represent the upper end of this range, while they are within the concentration range previously found at other sites in Thessaloniki $\left(1204 \pm 249 \mathrm{pg} \mathrm{m}^{-3}\right.$ at a traffic site and $383 \pm 77 \mathrm{pg} \mathrm{m}^{-3}$ at an urban background site; Besis et al., 2017). The total OPAH concentrations at both sites fall in the lower end of the range previously observed in Europe (0.5$50 \mathrm{ng} \mathrm{m}^{-3}$; Tomaz et al., 2016 and references therein).

NPAHs and OPAHs were predominant in the submicrometre $\mathrm{PM}$ fraction $\left(\mathrm{PM}_{0.95} ; 85 \%-91 \%\right.$ of $\mathrm{PM}_{10}$ at $\mathrm{MZ}$ and $78 \%-85 \%$ of total PM at the TK site; Figs. 1, 2, S3, $\mathrm{S} 4$ and S5), with relatively more enrichment in $\mathrm{PM}_{0.49}$ compared to $\mathrm{PM}_{0.49-0.95}$ across the two sites. The mean concentrations of $\sum$ NPAHs in $\mathrm{PM}_{0.49}$ from MZ and TK were $101 \pm$ 73 and $417 \pm 134 \mathrm{pg} \mathrm{m}^{-3}$, whereas in $\mathrm{PM}_{0.49-0.95}$ they were $22.8 \pm 15.9$ and $222 \pm 95 \mathrm{pg} \mathrm{m}^{-3}$, respectively. $\sum$ OPAHs showed similar patterns at the MZ and TK sites - they were $460 \pm 566$ and $1426 \pm 1210 \mathrm{pg} \mathrm{m}^{-3}$ in $\mathrm{PM}_{0.49}$, respectively, and $81.6 \pm 78.8$ and $555 \pm 209 \mathrm{pg} \mathrm{m}^{-3}$ in $\mathrm{PM}_{0.49-0.95}$. The targeted NPAHs did not show a second mode in any sample, whereas for 9-OFLN and 9,10- $\mathrm{O}_{2}$ ANT a second mode was found in MZ samples. Such differences between size distributions indicate that 9-OFLN and 9,10- $\mathrm{O}_{2}$ ANT are subject to different atmospheric processes compared to all other NPAHs and OPAHs that we studied in the present work. This could point at different emission and formation pathways in the atmosphere. Some of the OPAHs with a single $\mathrm{O}$ atom, namely OBAT, BaOFLN, and BbOFLN, originate from primary sources (i.e. combustion of fossil fuels and biomass; Albinet et al., 2007; Karavalakis et al., 2010; Shen et al., 2013b; Souza et al., 2014; Huang et al., 2014; Tomaz et al., 2016; Vicente et al., 2016), whereas some quinones, such as 9,10- $\mathrm{O}_{2}$ ANT and 1,2- $\mathrm{O}_{2}$ BAA, are associated with both primary and secondary sources (Kojima et al., 2010; Souza et al., 2014; Lin et al., 2015; Zhuo et al., 2017). The presence of 3-NFLT and 1-NPYR at TK indicates the influence of primary sources at that site (Bandowe and Meusel, 2017); notably, these two NPAHs were not found in MZ samples. In order to better understand the potential sources of the target substances, we performed correlation analysis between the measured levels of NPAHs and OPAHs and other PM constituents, namely, WSOC, HULIS, nitrate, sulfate, and $\mathrm{K}^{+}$. For this analysis, we considered the compositions of $\mathrm{PM}_{10}$ (at MZ) and total PM (at TK), as well as the constituents 

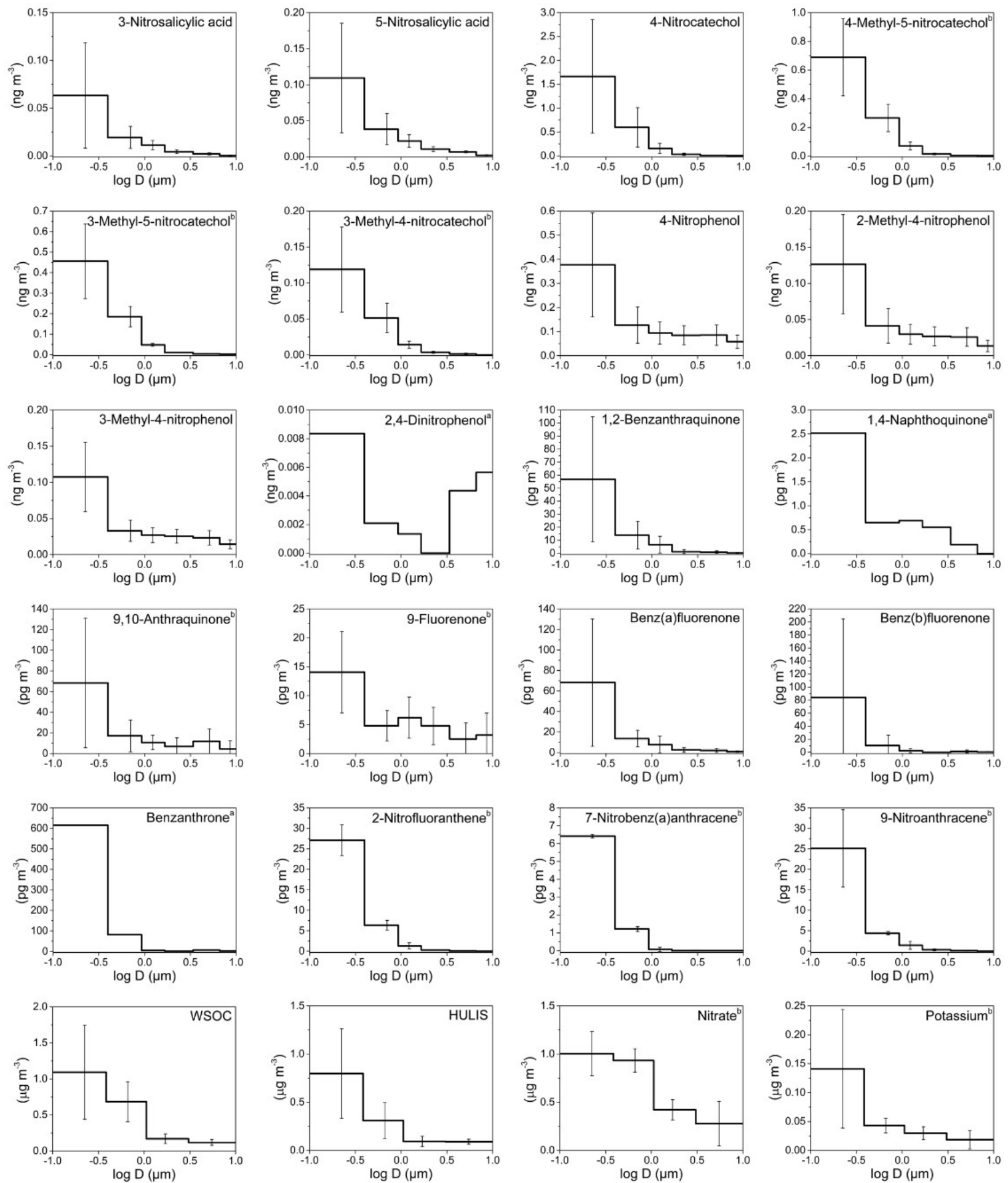

Figure 1. Mass size distributions (MSDs) of PM-bound NMAHs, NPAHs, OPAHs, WSOC, HULIS, and ions in Mainz (Germany). The error bars represent standard deviations. ${ }^{\text {a }}$ Compound MSD calculated from one (out of four) sample set (detected and quantified in one sample set only); ${ }^{\mathrm{b}}$ compound MSD calculated from three (out of four) sample sets (detected and quantified in three sample sets only). 

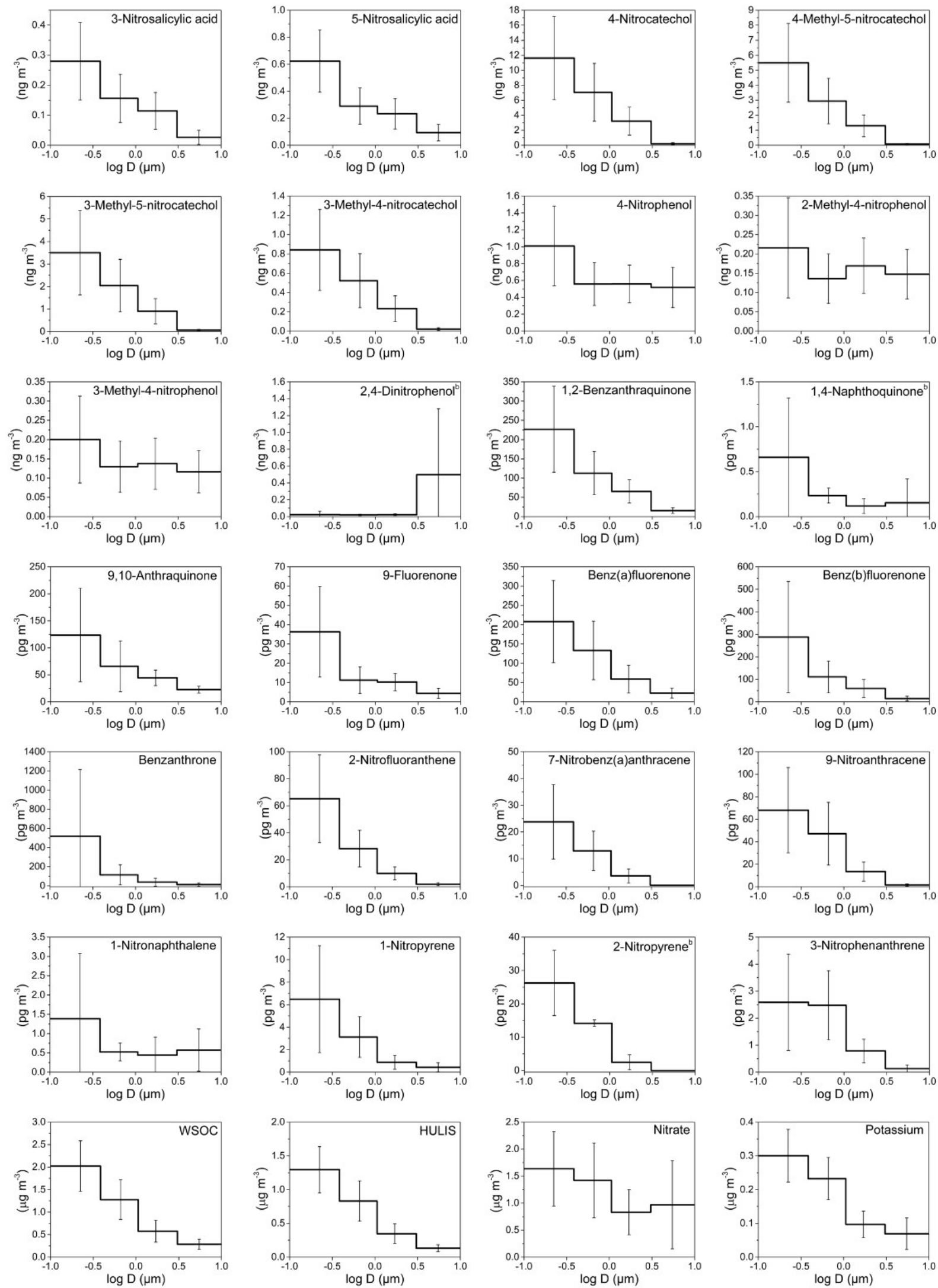

Figure 2. Mass size distributions (MSDs) of PM-bound NMAHs, NPAHs, OPAHs, WSOC, HULIS, and ions in Thessaloniki (Greece). The error bars represent standard deviations. ${ }^{\mathrm{b}}$ Compound MSD calculated from three (out of five) sample sets (detected and quantified in three sample sets only). 
of $\mathrm{PM}_{0.97}$ and $\mathrm{PM}_{3-0.97}$ at both sites. We found a significant correlation $(n=5 ; p<0.05)$ between $9,10-\mathrm{O}_{2}$ ANT and $1,2-\mathrm{O}_{2} \mathrm{BAA}$ at the TK site, regardless of the considered PM size range, which suggests a common emission source (Table S10). The data shown in Table S10 also indicate significant correlations $(p<0.05)$ between the levels of BaOFLN and 1-NPYR (produced by primary sources) and WSOC, HULIS, and $\mathrm{K}^{+}$(BB tracer) in the TK total PM samples. Considering the $\mathrm{PM}_{0.97}$ size fraction (Table S11), the correlation with $\mathrm{K}^{+}$was only significant for 1 -NPYR at TK, whereas both BaOFLN and 1-NPYR correlated with WSOC and HULIS in this size fraction. 1-NPYR is the predominant congener among NPAHs found in diesel engine exhaust particles and was proposed as a tracer for diesel emission (Bamford et al., 2003; IARC, 2013), but it may also be emitted with relatively small quantities from biomass-fuelled combustion (Shen et al., 2012; Orakij et al., 2017). These findings suggest the importance of primary emission sources including BB and diesel exhaust in the TK study area. For MZ $\mathrm{PM}_{10}$ samples, we found significant correlations $(n=4$; $p<0.05)$ of 9-OFLN, BaOFLN, and 9-NANT with WSOC and HULIS (Table S13) but no significant correlations to $\mathrm{K}^{+}$. We found similar correlations in $\mathrm{PM}_{0.97}$, which suggest the predominance of chemically aged air masses that were advected during the $M Z$ campaign. This is further supported by the absence of NPYR isomers in MZ samples, which are indicative of road traffic and industrial emissions (IARC, 1989; Finlayson-Pitts and Pitts, 2000; Lammel et al., 2017; Voliotis et al., 2017). Finally, $\mathrm{K}^{+}$, WSOC, and HULIS correlated significantly at TK $\left(p<0.05, R_{\text {adj }}^{2} 0.89-0.90\right)$, whereas such correlations were not found at MZ. In summary, while NPAHs and OPAHs from TK samples were influenced by primary emissions related to BB and fossil fuel combustion, those from MZ samples were dominated by aged air masses.

\subsection{Mass size distributions of target compounds}

\subsubsection{Mass size distributions of NMAHs}

MSDs of NMAHs over the two sampling locations are given in Figs. 1 and 2. NSAs (3-NSA and 5-NSA) and NCs (4NC, 4-M-5-NC, 3-M-5-NC, and 3-M-4-NC) showed unimodal distributions with MSDs generally peaking in the finest PM fraction $\left(\mathrm{PM}_{0.49}\right)$ in both $\mathrm{MZ}$ and $\mathrm{TK}$ samples. Overall, NMAHs were prominent in smaller size fractions $\left(\mathrm{PM}_{0.95}\right)$ in MZ compared to TK (Figs. 1 and 2). In one of the four samples collected at MZ, NSA MSDs peaked in $\mathrm{PM}_{1.5-0.95}$, while the $\mathrm{PM}_{0.95}$ mass fractions of 3-NSA and 5-NSA were $22 \%$ and $44 \%$, respectively (Fig. S1a). In this sample only, 5-NSA showed a bimodal distribution (dominant peaks in $\mathrm{PM}_{0.49}$ and $\mathrm{PM}_{1.5-0.95}$ ). Moreover, 4-NP and MNPs were the most abundant NMAHs (Fig. S1a); the abundance of 4-NP and MNPs could indicate the influence of primary traffic emissions (vehicle exhaust; Seki et al., 2010; Inomata et al., 2015; Lu et al., 2019b) at the beginning of the sampling campaign in MZ. During the next sampling periods at the MZ site (Fig. S1b, c and d), $75 \%-86 \%$ of NSAs' PM $_{10}$ mass was associated with $\mathrm{PM}_{0.95}$, which is in line with the observations at TK (66\%-82\% of total PM mass belongs to $\mathrm{PM}_{0.95}$; Fig. S2). At both sites, usually more than $90 \%$ of the compound total mass was associated with $\mathrm{PM}_{3}$ (range: $83 \%-$ $99 \%)$. We found that $87 \%-93 \%$ and $82 \%-88 \%$ of NCs at $\mathrm{MZ}$ and TK were associated with $\mathrm{PM}_{0.95}$ (Figs. S1, S2, and S5). The coarse mode ( $>3 \mu \mathrm{m}$ ) accounted for only $1 \%$ (MZ) or $2.5 \%$ (TK). The unimodal distributions of NCs peaking in the fine PM fraction are in line with the only report on MSDs of 4-NC (Li et al., 2016). The MSDs of HULIS in MZ and TK closely followed the MSDs of NCs and NSAs (Figs. 1 and 2), suggesting that they may have undergone similar atmospheric processes. The accumulation of the NCs' and NSAs' mass in the sub-micrometre $(<0.95 \mu \mathrm{m})$ PM fractions could indicate fresh combustion emissions (e.g. BB) and/or gas-to-particle conversion processes of their precursors over MZ and TK (Li et al., 2016).

Nitrophenols (i.e. 4-NP, 2-M-4-NP, and 3-M-4-NP) showed bimodal distributions with a dominant peak in the finest fraction $\left(\mathrm{PM}_{0.49}\right)$ and a smaller peak in $\mathrm{PM}_{3-0.95}$ (Figs. 1, 2, S1, S2 and S5). Bimodal distribution of NPs (i.e. 4-NP, 4-NG, 2,6-dimethyl-4-nitrophenol, and 2,6dinitrophenol), with peaks in the fine and coarse PM fractions, was recently reported during winter haze episodes over Shanghai, China (Li et al., 2016). For 4-NP at both sites, nearly $80 \%$ of the $\mathrm{PM}_{10}$ mass (or of the total PM mass at TK) was associated with $\mathrm{PM}_{3}$, while $\approx 60 \%$ was associated with $\mathrm{PM}_{0.95}$ (Figs. S1 and S2). Similarly, for methyl-nitrophenols $83 \%-88 \%$ of $\mathrm{PM}_{10}$ mass at $\mathrm{MZ}$ and $75 \%-83 \%$ of total PM mass at the TK site were associated with $\mathrm{PM}_{3}$, while $58 \%$ $65 \%$ of $\mathrm{PM}_{10}$ at $\mathrm{MZ}$ and $48 \%-61 \%$ of total PM mass at the TK site were associated with $\mathrm{PM}_{0.95}$ (Figs. S1 and S2).

The MMD of NMAHs was $0.10 \mu \mathrm{m}$ ( 0.24 for NPs, 0.07 for NCs, and $0.11 \mu \mathrm{m}$ for NSAs) at MZ vs. $0.27 \mu \mathrm{m}$ ( 0.60 for NPs, 0.24 for NCs, and $0.31 \mu \mathrm{m}$ for NSAs) at TK. The larger MMDs at TK could be indicative of aerosol ageing. In aged aerosols, semivolatile organic species are expected to be redistributed with the MMD approaching the surface mean diameter, which for urban and continental aerosol peaks around $0.2 \mu \mathrm{m}$ (Jaenicke, 1988), a shift which could not be resolved by the sampling technique applied here. Note that the low size resolution (six stages) may hide modes, which in particular applies to the so-called accumulation mode, which adds mostly to $\mathrm{PM}_{0.49}$ but also to the size fraction between 0.49 and $0.95 \mu \mathrm{m}$.

\subsubsection{Mass size distributions of NPAHs and OPAHs}

NPAH and OPAH MSDs are shown in Figs. 1 and 2. On average, the MMDs of NPAHs were $0.06 \mu \mathrm{m}$ at MZ and $0.12 \mu \mathrm{m}$ at TK, while those for OPAHs were $0.06 \mu \mathrm{m}$ at $\mathrm{MZ}$ and $0.10 \mu \mathrm{m}$ at TK. The MMDs for quinones were 0.07 and 0.15 at the two sites, respectively. We found two distinct MSD pat- 
terns among the samples: the first pattern observed in three samples across the two sites (one sample set from MZ and two sets from TK; Figs. S3c, S4a, d, and e) was dominated by OBAT followed by BbOFLN. The MMD of OPAHs in these three samples was on average $0.06 \mu \mathrm{m}$ (ranging within $0.05-0.09 \mu \mathrm{m})$. The unique analyte distribution in these samples was accompanied by a noticeably higher enrichment in $\mathrm{PM}_{0.49}$ as well as relatively high concentrations compared to the rest of samples. The preferential enrichment of OBAT, $\mathrm{BaOFLN}$, and BbOFLN in sub-micrometre PM was previously reported from locations in Europe, Asia, and the USA (Allen et al., 1997; Albinet et al., 2008; Ladji et al., 2009; Ringuet et al., 2012; Shen et al., 2016; Gao et al., 2019). The second pattern, which was seen in the remaining six sample sets, was considerably different: the target substances were more evenly distributed across different PM size ranges, and they were often dominated by relatively high abundance of quinones $9,10-\mathrm{O}_{2} \mathrm{ANT}$ and $1,2-\mathrm{O}_{2} \mathrm{BAA}$ - the two quinones were previously reported with preferential enrichment in ultrafine PM (Ringuet et al., 2012; Shen et al., 2016). The MMD of OPAHs in these five sample sets was on average $0.25 \mu \mathrm{m}$ (ranging within $0.08-0.49 \mu \mathrm{m}$ ).

In terms of the inter-site variability of the target substance MSDs, the size fraction $\mathrm{PM}_{0.49}$ was more prominent in MZ than in TK, i.e. on average $74 \%$ for NPAHs, $75 \%$ for OPAHs, and $69 \%$ for quinones at MZ, compared to $55 \%$, $60 \%$, and $52 \%$, respectively, at the TK site (Figs. 1-2 and S3-S5). The largest differences found among each substance group were for 9-NANT ( $28 \%$ higher at MZ), BbOFLN ( $25 \%$ higher), and $1,2-\mathrm{O}_{2}$ BAA (17\% higher). The values for NPAHs from TK were lower than those previously found for wintertime PM at this site $(59 \%$ and $71 \%$ for a traffic and urban background site, respectively; Besis et al., 2017). The higher enrichment of predominant NPAHs (9-NANT and 2-NFLT; Figs. S3-S4) in $\mathrm{PM}_{0.49}$ in the present study is in agreement with the MSDs reported for these compounds from several other locations in Europe and Asia (Ringuet et al., 2012; Lan et al., 2014; Lammel et al., 2017). The preferential enrichment of NPAHs and OPAHs in sub-micrometre $\mathrm{PM}$, especially $\mathrm{PM}_{0.49}$, raises concerns with respect to the inhalation toxicity of airborne PM; this is due to the fact that $\mathrm{PM}_{0.49}$ is capable of reaching deeper regions in the lung (Oberdörster et al., 2005). This is exacerbated by the ability of quinones to catalyse redox reactions and the formation of ROS in the respiratory system (Ayres et al., 2008).

\subsection{NMAHs as part of HULIS}

Because of their water solubility, NMAHs are constituents of PM HULIS and WSOC (Claeys et al., 2012; Teich et al., 2017). This substance class contributed $\approx 0.4 \%$ and $1.8 \%$ to HULIS mass at the MZ and TK sites, respectively (Table 3). This contribution was fairly even across the size fractions addressed, while showing a maximum for particles size $0.95-3 \mu \mathrm{m}$, namely $\approx 0.7 \%$ and $2.0 \%$ by mass at the $\mathrm{MZ}$
Table 3. Mean absolute concentrations and mass mixing ratios (in brackets) of HULIS ${ }^{\mathrm{a}}$ in WSOC $^{\mathrm{a}}$ as well as of NMAHs in HULIS in (a) Mainz and (b) Thessaloniki PM.

\begin{tabular}{|c|c|c|c|}
\hline $\begin{array}{l}\text { (a) } \\
\text { Particle size } \\
(\mu \mathrm{m})\end{array}$ & $\begin{array}{r}\text { WSOC } \\
\mu \mathrm{gC} \mathrm{m}^{-3}\end{array}$ & $\begin{array}{r}\text { HULIS } \mu \mathrm{g} \mathrm{m}^{-3} \\
(\% \mathrm{C} / \mathrm{C})^{\mathrm{b}}\end{array}$ & $\begin{array}{r}\text { NMAHs ng m-3 } \\
(\%)\end{array}$ \\
\hline$<0.49$ & 1.14 & $0.80(39)$ & $3.41(0.43)$ \\
\hline $0.49-0.95$ & 0.68 & $0.31(25)$ & $1.24(0.40)$ \\
\hline $0.95-3$ & 0.18 & $0.09(28)$ & $0.65(0.73)$ \\
\hline $3-10$ & 0.12 & $0.09(42)$ & $0.27(0.30)$ \\
\hline Total & 2.07 & $1.29(33)$ & $5.58(0.43)$ \\
\hline
\end{tabular}

\begin{tabular}{lrrr}
\hline $\begin{array}{l}\text { (b) } \\
\text { Particle size } \\
(\mu \mathrm{m})\end{array}$ & $\begin{array}{r}\mathrm{WSOC}^{-3} \\
\mu \mathrm{gC} \mathrm{m}{ }^{-3}\end{array}$ & $\begin{array}{r}\text { HULIS } \mu \mathrm{g} \mathrm{m}^{-3} \\
(\% \mathrm{C} / \mathrm{C})\end{array}$ & $\begin{array}{r}\mathrm{NMAHs} \mathrm{ng} \mathrm{m}^{-3} \\
(\%)\end{array}$ \\
\hline$<0.49$ & 2.02 & $1.29(34)$ & $24.0(1.9)$ \\
$0.49-0.95$ & 1.28 & $0.83(34)$ & $13.9(1.7)$ \\
$0.95-3$ & 0.57 & $0.35(32)$ & $6.89(2.0)$ \\
$>3$ & 0.33 & $0.11(18)$ & $1.87(1.7)$ \\
\hline Total & 4.20 & $2.58(32)$ & $46.6(1.8)$ \\
\hline
\end{tabular}

a Voliotis et al. (2017). ${ }^{\mathrm{b}}$ Fraction (\%) of HULIS carbon in organic carbon.

and TK sites, respectively. The large particle size, $0.95-3 \mu \mathrm{m}$, points to the significance of aqueous-phase processes and in general the slower formation of NMAHs (Voliotis et al., 2017). The activation of condensation-mode particles (under high humidity) into cloud droplets, as well as the subsequent possible aqueous-phase reactions, leads to the formation of larger particles in aged and cloud-processed aerosols. In central Europe, characteristic times of formation of coarse-mode secondary inorganic aerosols and OC peak around $60-72 \mathrm{~h}$ (Lammel et al., 2003).

Our reported NMAH contribution to HULIS mass is in good agreement with the results of previous reports from urban sites in Europe (Kitanovski et al., 2012b; Claeys et al., 2012) and Brazil (Caumo et al., 2016). Specifically, Kitanovski et al. (2012b) found that NMAHs contributed $0.4 \%-1.3 \%$ to the OC mass in winter $\mathrm{PM}_{10}$ from Ljubljana (Slovenia), while in another study 4-NC alone contributed $0.46 \%$ and $0.04 \%$ to the HULIS mass in urban spring and summer $\mathrm{PM}_{2.5}$ from Budapest, Hungary, respectively (Claeys et al., 2012). Moreover, NMAHs (4-NP, 4-NC, MNCs, and dimethyl-nitrocatechols; DMNCs) contributed $0.28 \%$ and $0.35 \%$ to the OC mass in winter $\mathrm{PM}_{10}$ samples from São Paulo, Brazil (Caumo et al., 2016). Lower NMAH contribution to HULIS (or OC) mass were reported for rural sites in Europe. For example, 4-NC contributed $0.03 \%$ to the HULIS mass in summer $\mathrm{PM}_{2.5}$ from K-puszta, Hungary (Claeys et al., 2012), while total NMAHs (NPs, 4-NC, MNCs, and DMNCs) represented $0.75 \%$ of OC mass in winter $\mathrm{PM}_{10}$ sampled at a rural background site in Belgium (Kahnt et al., 2013). 
In Sect. 3.2.1, we emphasized the similar MSDs at both locations between HULIS on one side and NCs and NSAs on the other. These two NMAH subclasses on average contributed to $\approx 83 \%$ and $\approx 94 \%$ of total NMAHs in $\mathrm{PM}_{0.95}$ and $\approx 55 \%$ and $87 \%$ of total NMAHs in $\mathrm{PM}_{3-0.95}$ at the MZ and TK sites, respectively (Table S16). At both sites, $\mathrm{NCs}$ were the dominant NMAH species. It is also interesting to note that HULIS showed higher correlations with NSAs and NCs in MZ $\left(0.68<R_{\text {adj }}^{2}<0.98\right.$; Table S7) than in TK $\left(0.24<R_{\text {adj }}^{2}<0.59 ;\right.$ Table S4).

With mass mixing ratios of the order of $1 \%$, NMAHs are constituents of HULIS with limited significance by mass, but their relevance is more significant due to their optical properties (Mohr et al., 2013; Laskin et al., 2015; Teich et al., 2017; Xie et al., 2017). Teich et al. (2017) found that the mass contributions of total NMAHs (NPs and NSAs) to WSOC on average was five times lower than their contribution to the light absorption of the aqueous PM extract at $370 \mathrm{~nm}$ (Teich et al., 2017). This implies that even small fractions of chromophoric HULIS compounds such as NMAHs can have an excessive influence on the aerosol light absorption (Mohr et al., 2013; Teich et al., 2017) and the atmospheric photochemical processes, especially in polluted areas (Laskin et al., 2015; Teich et al., 2017).

\section{Final remarks}

We studied the composition and MSDs of NMAHs, NPAHs, and OPAHs in PM from urban locations in Germany and Greece, with some of the target substances (i.e. NSAs, MNCs, and MNPs) studied in size-resolved PM for the first time. At both locations, NCs were the most abundant NMAH species, and OPAHs were more abundant and more frequently detected than NPAHs. The total concentrations of the most abundant NMAHs, NCs, NPAHs, and OPAHs were up to 10 times higher in TK than in MZ. Correlation analysis of NMAHs revealed distinct features among the sites, suggesting mixed air masses influenced by fresh BB and fossil fuel combustion emissions at TK and aged advected air influenced by combustion emissions (i.e. BB and coal combustion) at MZ.

The MSDs of NMAHs, OPAHs, and NPAHs were rather similar, but they exhibited temporal and spatial variations due to daily changes in atmospheric conditions and different sources. In general, NCs, NSAs, OPAHs, and NPAHs showed unimodal MSDs peaking in the finest PM fraction, $\mathrm{PM}_{0.49}$, which was more prominent in MZ than in TK. NPs exhibited bimodal MSDs with the dominant peak in $\mathrm{PM}_{0.49}$. The MMDs of all chemical classes were lower at MZ than at TK; the larger MMDs at TK could be an indication of aerosol ageing. On average, NMAHs contributed up to $1.8 \%$ to the HULIS mass in the study areas. Although NMAHs represent a small fraction of PM HULIS (and WSOC), due to their light absorption properties, their impact on the total aerosol light absorption could be disproportionally large. This is particularly important for atmospheric photochemical processes in polluted areas.

Data availability. The dataset used in this paper is included in the Supplement, and further information is available from the corresponding authors (z.kitanovski@mpic.de; p.shahpoury@mpic.de).

Supplement. The supplement related to this article is available online at: https://doi.org/10.5194/acp-20-2471-2020-supplement.

Author contributions. GL and CS conceived the study. PS and AV conducted the air sampling and field measurements. ZK and PS did the chemical analysis of samples. ZK, PS, and GL did the data analysis. ZK, PS, and GL discussed the results and wrote the paper with input from all co-authors.

Competing interests. The authors declare that they have no conflict of interest.

Acknowledgements. We thank Eleni Papakosta (prefecture of Thessaloniki), Thorsten Hoffmann, and Anna Honcza (Max Planck Institute for Chemistry) for on-site and laboratory support. This research was supported by the Max Planck Society and the postgraduate programme "Environmental Chemistry and Pollution Control" of the Aristotle University of Thessaloniki

Financial support. The article processing charges for this openaccess publication were covered by the Max Planck Society.

Review statement. This paper was edited by Alexander Laskin and reviewed by two anonymous referees.

\section{References}

Albinet, A., Leoz-Garziandia, E., Budzinski, H., and ViIlenave, E. Polycyclic aromatic hydrocarbons (PAHs), nitrated PAHs and oxygenated PAHs in ambient air of the Marseilles area (South of France): concentrations and sources, Sci. Total Environ., 384, 280-292, https://doi.org/10.1016/j.scitotenv.2007.04.028, 2007.

Albinet, A., Leoz-Garziandia, E., Budzinski, H., Villenave, E., and Jaffrezo, J.-L.: Nitrated and oxygenated derivatives of polycyclic aromatic hydrocarbons in the ambient air of two French alpine valleys Part 2: particle size distribution, Atmos. Environ., 42, 5564, https://doi.org/10.1016/j.atmosenv.2007.10.008, 2008.

Albinet, A., Nalin, F., Tomaz, S., Beaumont, J., and Lestremau, F.: A simple QuEChERS-like extraction approach for molecular chemical characterization of organic aerosols: application to nitrated and oxygenated PAH derivatives (NPAH and OPAH) quan- 
tified by GC-NICIMS, Anal. Bioanal. Chem., 406, 3131-3148, https://doi.org/10.1007/s00216-014-7760-5, 2014.

Allen, J. O., Dookeran, N. M., Taghizadeh, K., Lafleur, K. L., Smitz, K. A., and Sarofim, A. F.: Measurement of oxygenated polycyclic aromatic hydrocarbons associated with a sizesegregated urban aerosol, Environ. Sci. Technol., 31, 2064-2070, https://doi.org/10.1021/es960894g, 1997.

al-Naiema, I. M. and Stone, E. A.: Evaluation of anthropogenic secondary organic aerosol tracers from aromatic hydrocarbons, Atmos. Chem. Phys., 17, 2053-2065, https://doi.org/10.5194/acp17-2053-2017, 2017.

Andreae, M. O. and Gelencsér, A.: Black carbon or brown carbon? The nature of light-absorbing carbonaceous aerosols, Atmos. Chem. Phys., 6, 3131-3148, https://doi.org/10.5194/acp-63131-2006, 2006.

Antiñolo, M., Willis, M. D., Zhou, S., and Abbatt, J. P. D.: Connecting the oxidation of soot to its redox cycling abilities, Nat. Commun., 6, 6812, https://doi.org/10.1038/ncomms7812, 2015.

Ayres, J. G., Borm, P., Cassee, F. R., Castranova, V., Donaldson, K., Ghio, A., Harrison, R. M., Hider, R., Kelly, F., Kooter, I. M., Marano, F., Maynard, R. L., Mudway, I., Nel, A., Sioutas, C., Smith, S., Baeza-Squiban, A., Cho, A., Duggan, S., and Froines, J.: Evaluating the toxicity of airborne particulate matter and nanoparticles by measuring oxidative stress potential a workshop report and consensus statement, Inhal. Toxicol., 20, 75-99, https://doi.org/10.1080/08958370701665517, 2008.

Bamford, H. A., Bezabeh, D. Z., Schantz, M. M., Wise, S. A., and Baker, J. E.: Determination and comparison of nitratedpolycyclic aromatic hydrocarbons measured in air and diesel particulate reference materials, Chemosphere, 50, 575-587, https://doi.org/10.1016/S0045-6535(02)00667-7, 2003.

Bandowe, B. A. M. and Meusel, H.: Nitrated polycyclic aromatic hydrocarbons (nitro-PAHs) in the environment - a review, Sci. Total Environ., 581-582, 237-257, https://doi.org/10.1016/j.scitotenv.2016.12.115, 2017.

Bates, J. T., Fang, T., Verma, V., Zeng, L., Weber, R. J., Tolbert, P. E., Abrams, J. Y., Sarnat, S. E., Klein, M., Mulholland, J. A., and Russell, A. G.: Review of acellular assays of ambient particulate matter oxidative potential: methods and relationships with composition, sources, and health effects, Environ. Sci. Technol., 53, 4003-4019, https://doi.org/10.1021/acs.est.8b03430, 2019.

Besis, A., Tsolakidou, A., Balla, D., Samara, C., Voutsa, D., Pantazaki, A., Choli-Papadopoulou, T., and Lialiaris, T. S.: Toxic organic substances and marker compounds in size-segregated urban particulate matter - implications for involvement in the in vitro bioactivity of the extractable organic matter, Environ. Pollut., 230, 758-774, https://doi.org/10.1016/j.envpol.2017.06.096, 2017.

Caumo, S. E. S., Claeys, M., Maenhaut, W., Vermeylen, R., Shabnam, B., Shalamzari, M. S., and Vasconcellos, P. C.: Physicochemical characterization of winter $\mathrm{PM}_{10}$ aerosol impacted by sugarcane burning from São Paulo city, Atmos. Environ., 145, 272-279, https://doi.org/10.1016/j.atmosenv.2016.09.046, 2016.

Cecinato, A., di Palo, V., Pomata, D., Scianò, M. C. T., and Possanzini, M.: Measurement of phase-distributed nitrophenols in Rome ambient air, Chemosphere, 59, 679-683, https://doi.org/10.1016/j.chemosphere.2004.10.045, 2005.

Chow, K. S., Hilda, X. H. H., and Yu, J. Z.: Quantification of nitroaromatic compounds in atmospheric fine particulate matter in Hong Kong over 3 years: field measurement evidence for secondary formation derived from biomass burning emissions, Environ. Chem., 13, 665-673, https://doi.org/10.1071/EN15174, 2016.

Claeys, M., Vermeylen, R., Yasmeen, F., Gómez-González, Y., Chi, X., Maenhaut, W., Mészáros, T., and Salma, I.: Chemical characterisation of humic-like substances from urban, rural and tropical biomass burning environments using liquid chromatography with UV/vis photodiode array detection and electrospray ionisation mass spectrometry, Environ. Chem., 9, 273-284, https://doi.org/10.1071/EN11163, 2012.

Decesari, S., Facchini, M. C., Fuzzi, S., and Tagliavini, E.: Characterization of water-soluble organic compounds in atmospheric aerosol: a new approach, J. Geophys. Res., 105, 1481-1489, https://doi.org/10.1029/1999JD900950 2000.

Ding, J., Zhong, J., Yang, Y., Li, B., Shen, G., Su, Y., Wang, C., Li, W., Shen, H., Wang, B., Wang, R., Huang, Y., Zhang, Y., Cao, H., Zhu, Y., Simonich, S. L. M., and Tao, S.: Occurrence and exposure to polycyclic aromatic hydrocarbons and their derivatives in a rural Chinese home through biomass fuelled cooking, Environ. Pollut., 169, 160-166, https://doi.org/10.1016/j.envpol.2011.10.008, 2012.

Duarte, R. M. B. O., Pio, C. A., and Duarte, A. C.: Spectroscopic study of the water-soluble organic matter isolated from atmospheric aerosols collected under different atmospheric conditions, Anal. Chim. Acta, 530, 7-14, https://doi.org/10.1016/j.aca.2004.08.049, 2005.

Dusek, U., Frank, G. P., Hildebrandt, L., Curtius, J., Schneider, J., Walter, S., Chand, D., Drewnick, F., Hings, S., Jung, D., Borrmann, S., and Andreae, M.O.: Size matters more than chemistry for cloud nucleating ability of aerosol particles, Science, 312, 1375-1378, https://doi.org/10.1126/science.1125261, 2006.

Fan, X., Wei, S., Zhu, M., Song, J., and Peng, P.: Comprehensive characterization of humic-like substances in smoke $\mathrm{PM}_{2.5}$ emitted from the combustion of biomass materials and fossil fuels, Atmos. Chem. Phys., 16, 13321-13340, https://doi.org/10.5194/acp-16-13321-2016, 2016.

Finewax, Z., de Gouw, J. A., and Ziemann, P. J.: Identification and quantification of 4-nitrocatechol formed from $\mathrm{OH}$ and $\mathrm{NO}_{3}$ radical-initiated reactions of catechol in air in the presence of $\mathrm{NO}_{\mathrm{x}}$ : implications for secondary organic aerosol formation from biomass burning, Environ. Sci. Technol., 52, 1981-1988, https://doi.org/10.1021/acs.est.7b05864, 2018.

Finlayson-Pitts, B. J. and Pitts, J. N.: Chemistry of the Upper and Lower Atmosphere: Theory, Experiments, Application, San Diego, Academic Press, USA, 2000.

Frka, S., Šala, M., Kroflič, A., Huš, M., Čusak, A., and Grgić, I.: Quantum chemical calculations resolved identification of methylnitrocatechols in atmospheric aerosols, Environ. Sci. Technol., 50, 5526-5535, https://doi.org/10.1021/acs.est.6b00823, 2016.

Ganranoo, L., Mishra, S. K., Azad, A. K., Shigihara, A., Dasgupta, P. K., Breitbach, Z. S., Armstrong, D. W., Grudpan, K., and Rappenglück, B.: Measurement of nitrophenols in rain and air by two-dimensional liquid chromatography-chemically active liquid core waveguide spectrometry, Anal. Chem., 82, 5838-5843, https://doi.org/10.1021/ac101015y, 2010.

Gao, Y., Lyu, Y., and Li, X.: Size distribution of airborne particle-bound PAHs and o-PAHs and their implications for 
dry deposition, Environ. Sci. Process. Impacts, 21, 1184-1192, https://doi.org/10.1039/c9em00174c, 2019.

Graber, E. R. and Rudich, Y.: Atmospheric HULIS: How humiclike are they? A comprehensive and critical review, Atmos. Chem. Phys., 6, 729-753, https://doi.org/10.5194/acp-6-7292006, 2006.

Hallquist, M., Wenger, J. C., Baltensperger, U., Rudich, Y., Simpson, D., Claeys, M., Dommen, J., Donahue, N. M., George, C., Goldstein, A. H., Hamilton, J. F., Herrmann, H., Hoffmann, T., Iinuma, Y., Jang, M., Jenkin, M. E., Jimenez, J. L., Kiendler-Scharr, A., Maenhaut, W., McFiggans, G., Mentel, Th. F., Monod, A., Prévôt, A. S. H., Seinfeld, J. H., Surratt, J. D., Szmigielski, R., and Wildt, J.: The formation, properties and impact of secondary organic aerosol: current and emerging issues, Atmos. Chem. Phys., 9, 5155-5236, https://doi.org/10.5194/acp9-5155-2009, 2009.

Harrison, M. A. J., Barra, S., Borghesi, D., Vione, D., Arsene, C., and Olariu, R. I.: Nitrated phenols in the atmosphere: a review, Atmos. Environ., 39, 231-248, https://doi.org/10.1016/j.atmosenv.2004.09.044, 2005.

Havers, N., Burba, P., Lambert, J., and Klockow, D.: Spectroscopic characterization of humic-like substances in airborne particulate matter, J. Atmos. Chem., 29, 45-54, https://doi.org/10.1023/A:1005875225800, 1998.

Haynes, J. P., Miller, K. E., and Majestic, B. J.: Investigation into photoinduced auto-oxidation of polycyclic aromatic hydrocarbons resulting in brown carbon production, Environ. Sci. Technol., 53, 682-691, https://doi.org/10.1021/acs.est.8b05704, 2019.

Hoffmann, D., Iinuma, Y., and Herrmann, H.: Development of a method for fast analysis of phenolic molecular markers in biomass burning particles using high performance liquid chromatography/atmospheric pressure chemical ionisation mass spectrometry, J. Chromatogr. A, 1143, 168-175, https://doi.org/10.1016/j.chroma.2007.01.035, 2007.

Huang, R.-J., Yang, L., Cao, J., Chen, Y., Chen, Q., Li, Y., Duan, J., Zhu, Ch., Dai, W., Wang, K., Lin, Ch., Ni, H., Corbin, J. C., Wu, Y., Zhang, R., Tie, X., Hoffmann, T., O’Dowd, C., and Dusek, U.: Brown carbon aerosol in urban Xi' an, Northwest China: The composition and light absorption properties, Environ. Sci. Technol., 52, 6825-6833, https://doi.org/10.1021/acs.est.8b02386, 2018

Huang, W., Huang, B., Bi, X., Lin, Q., Liu, M., Ren, Z., Zhang, G., Wang, X., Sheng, G., and Fu, J.: Emission of PAHs, NPAHs and OPAHs from residential honeycomb coal briquette combustion, Energy Fuels, 28, 636-642, https://doi.org/10.1021/ef401901d, 2014.

IARC: Diesel and gasoline engine exhausts and some nitroarenes, IARC Monographs on the Evaluation of Carcinogenic Risks to Humans, Vol. 46, International Agency for Research on Cancer, Lyon, 1989.

IARC: Diesel and Gasoline Engine Exhausts and Some Nitroarenes, IARC Monographs on the Evaluation of Carcinogenic Risks to Humans, Vol. 105, International Agency for Research on Cancer, Lyon, 2013.

Iinuma, Y., Brüggemann, E., Gnauk, T., Müller, K., Andreae, M. O., Helas, G., Parmar, R., and Herrmann, H.: Source characterization of biomass burning particles: the combustion of selected European conifers, African hardwood, savanna grass, and
German and Indonesian peat, J. Geophys. Res., 112, D8209, https://doi.org/10.1029/2006JD007120, 2007.

Iinuma, Y., Böge, O., Gräfe, R., and Herrmann, H.: Methylnitrocatechols: atmospheric tracer compounds for biomass burning secondary organic aerosols, Environ. Sci. Technol., 44, 8453-8459, https://doi.org/10.1021/es102938a, 2010.

Iinuma, Y., Keywood, M., and Herrmann, H: Characterization of primary and secondary organic aerosols in Melbourne airshed: the influence of biogenic emissions, wood smoke and bushfires, Atmos. Environ., 130, 54-63, https://doi.org/10.1016/j.atmosenv.2015.12.014, 2016.

Inomata, S., Fushimi, A., Fujitani, Y., and Yamada, H.: 4-Nitrophenol, 1-nitropyrene, and 9-nitroanthracene emissions in exhaust particles from diesel vehicles with different exhaust gas treatments, Atmos. Environ., 110, 93-102, https://doi.org/10.1016/j.atmosenv.2015.03.043, 2015.

Jaenicke, R.: Aerosol physics and chemistry, Landolt-Börnstein Neue Ser., 4b, 391-457, 1988.

Kahnt, A., Behrouzi, S., Vermeylen, R., Shalamzari, M.S., Vercauteren, J., Roekens, E., Claeys, M., and Maenhaut, W.: One-year study of nitro-organic compounds and their relation to wood burning in $\mathrm{PM}_{10}$ aerosol from a rural site in Belgium, Atmos. Environ., 81, 561-568, https://doi.org/10.1016/j.atmosenv.2013.09.041, 2013.

Karavalakis, G., Deves, G., Fontaras, G., Stournas, S., Samaras, Z., and Bakeas, E.: The impact of soy-based biodiesel on PAH, nitro$\mathrm{PAH}$ and oxy-PAH emissions from a passenger car operated over regulated and nonregulated driving cycles, Fuel, 89, 3876-3883, https://doi.org/10.1016/j.fuel.2010.07.002, 2010.

Kelly, J. L., Michelangeli, D. V., Makar, P. A., Hastie, D. R., Mozurkewich, M., and Auld, J.: Aerosol speciation and mass prediction from toluene oxidation under high $\mathrm{NO}_{\mathrm{x}}$ conditions, Atmos. Environ., 44, 361-369, https://doi.org/10.1016/j.atmosenv.2009.10.035, 2010.

Kitanovski, Z., Grgić, I., Yasmeen, F., Claeys, M., and Čusak, A.: Development of a liquid chromatographic method based on ultraviolet-visible and electrospray ionization mass spectrometric detection for the identification of nitrocatechols and related tracers in biomass burning atmospheric organic aerosol, Rapid Commun. Mass Sp., 26, 793-804, https://doi.org/10.1002/rcm.6170, 2012a.

Kitanovski, Z., Grgić, I., Vermeylen, R., Claeys, M., and Maenhaut, W.: Liquid chromatography tandem mass spectrometry method for characterization of monoaromatic nitro-compounds in atmospheric particulate matter, J. Chromatogr. A, 1268, 35-43, https://doi.org/10.1016/j.chroma.2012.10.021, 2012b.

Kojima, Y., Inazu, K., Hisamatsu, Y., Okochi, H., Baba, T., and Nagoya, T.: Influence of secondary formation on atmospheric occurrences of oxygenated polycyclic aromatic hydrocarbons in airborne particles, Atmos. Environ., 44, 2873-2880, https://doi.org/10.1016/j.atmosenv.2010.04.048, 2010.

Kourtchev, I., O'Connor, I. P., Giorio, C., Fuller, S. J., Kristensen, K., Maenhaut, W., Wenger, J. C., Sodeau, J. R., Glasius, M., and Kalberer, M.: Effects of anthropogenic emissions on the molecular composition of urban organic aerosols: An ultrahigh resolution mass spectrometry study, Atmos. Environ., 89, 525-532, https://doi.org/10.1016/j.atmosenv.2014.02.051, 2014.

Kroflič, A., Grilc, M., and Grgić, I.: Unraveling pathways of guaiacol nitration in atmospheric waters: nitrite, a source of reac- 
tive nitronium ion in the atmosphere, Environ. Sci. Technol., 49, 9150-9158, https://doi.org/10.1021/acs.est.5b01811, 2015.

Ladji, R., Yassaa, N., Balducci, C., Cecinato, A., and Meklati, B. Y.: Distribution of the solvent-extractable organic compounds in fine (PM1) and coarse (PM1-10) particles in urban, industrial and forest atmospheres of Northern Algeria, Sci. Total Environ., 408, 415-424, https://doi.org/10.1016/j.scitotenv.2009.09.033, 2009.

Lammel, G.: Polycyclic aromatic compounds in the atmosphere a review identifying research needs, Polycyclic Aromat. Comp., 35, 316-329, https://doi.org/10.1080/10406638.2014.931870, 2015.

Lammel, G., Brüggemann, E., Gnauk, T., Müller, K., Neusüß, C., and Röhrl, A.: A new method to study aerosol source contributions along the tracts of air parcels and its application to the near-ground level aerosol chemical composition in central Europe, J. Aerosol Sci., 34, 1-25, https://doi.org/10.1016/S00218502(02)00134-9, 2003.

Lammel, G., Mulder, M. D., Shahpoury, P., Kukučka, P., Lišková, H., Přibylová, P., Prokeš, R., and Wotawa, G.: Nitro-polycyclic aromatic hydrocarbons - gas-particle partitioning, mass size distribution, and formation along transport in marine and continental background air, Atmos. Chem. Phys., 17, 6257-6270, https://doi.org/10.5194/acp-17-6257-2017, 2017.

Lan, S. H., Lan, H. X., Yang, D., and Wu, X. W.: Study of nitro-polycyclic aromatic hydrocarbons in particulate matter in Dongguan, Environ. Sci. Pollut. R., 21, 7390-7399, https://doi.org/10.1007/s11356-014-2644-y, 2014.

Laskin, A., Laskin, J., and Nizkorodov, S. A.: Chemistry of atmospheric brown carbon, Chem. Rev., 115, 4335-4382, https://doi.org/10.1021/cr5006167, 2015.

Li, Q., Wyatt, A., and Kamens, R. M.: Oxidant generation and toxicity enhancement of aged-diesel exhaust, Atmos. Environ., 43, 1037-1042, https://doi.org/10.1016/j.atmosenv.2008.11.018, 2009.

Li, X., Jiang, L., Hoa, L.P., Lyu, Y., Xu, T., Yang, X., Iinuma, Y., Chen, J., and Herrmann, H.: Size distribution of particlephase sugar and nitrophenol tracers during severe urban haze episodes in Shanghai, Atmos. Environ., 145, 115-127, https://doi.org/10.1016/j.atmosenv.2016.09.030, 2016.

Lin, P., Huang, X. F., He, L. Y., and Yu, J. Z.: Abundance and size distribution of HULIS in ambient aerosols at a rural site in South China, J. Aerosol Sci., 41, 74-87, https://doi.org/10.1016/j.jaerosci.2009.09.001, 2010.

Lin, Y., Ma, Y., Qiu, X., Li, R., Fang, Y., Wang, J., Zhu, Y., and $\mathrm{Hu}, \mathrm{D}$.: Sources, transformation, and health implications of PAHs and their nitrated, hydroxylated, and oxygenated derivatives in $\mathrm{PM}_{2.5}$ in Beijing, J. Geophys. Res., 120, 7219-7228, https://doi.org/10.1002/2015JD023628, 2015.

Lu, Ch., Wang, X., Li, R., Gu, R., Zhang, Y., Li, W., Gao, R., Chen, B., Xue, L., and Wang, W.: Emissions of fine particulate nitrated phenols from residential coal combustion in China, Atmos. Environ., 203, 10-17, https://doi.org/10.1016/j.atmosenv.2019.01.047, 2019a.

Lu, Ch., Wang, X., Dong, Sh., Zhang, J., Li, J., Zhao, Y., Liang, Y., Xue, L., Xie, H., Zhang, Q., and Wang, W.: Emissions of fine particulate nitrated phenols from various on-road vehicles in China, Environ. Res., 179, 108709, https://doi.org/10.1016/j.envres.2019.108709, 2019 b.
McWhinney, R. D., Gao, S. S., Zhou, S., and Abbatt, J. P. D.: Evaluation of the effects of ozone oxidation on redox-cycling activity of two-stroke engine exhaust particles, Environ. Sci. Technol., 45, 2131-2136, https://doi.org/10.1021/es102874d, 2011.

Mohr, C., Lopez-Hilfiker, F. D., Zotter, P., Prévôt, A. S. H., Xu, L., Ng, N. L., Herndon, S. C., Williams, L. R., Franklin, J. P., Zahniser, M. S., Worsnop, D. R., Knighton, W. B., Aiken, A. C., Gorkowski, K. J., Dubey, M. K., Allan, J. D., and Thornton, J. A.: Contribution of nitrated phenols to wood burning brown carbon light absorption in Detling, United Kingdom during winter time, Environ. Sci. Technol., 47, 6316-6324, https://doi.org/10.1021/es400683v, 2013.

Neusüss, C., Pelzing, M., Plewka, A., and Herrmann, H.: A new analytical approach for size-resolved speciation of organic compounds in atmospheric aerosol particles: methods and first results, J. Geophys. Res., 105, 4513-4527, https://doi.org/10.1029/1999JD901038, 2000.

Noguchi, K., Toriba, A., Chung, S. W., Kizu, R., and Hayakawa, K.: Identification of estrogenic/anti-estrogenic compounds in diesel exhaust particulate extract, Biomed. Chromatogr., 21, 11351142, https://doi.org/10.1002/bmc.861, 2007.

Oberdörster, G., Oberdörster, E., and Oberdörster, J.: Nanotoxicology: an emerging discipline evolving from studies of ultrafine particles, Environ. Health Persp., 113, 823-839, 2005.

Orakij, W., Chetiyanukornkul, T., Kasahara, C., Boongla, Y., Chuesaard, T., Furuuchi, M., Hata, M., Tang, N., Hayakawa, K., and Toriba, A.: Polycyclic aromatic hydrocarbons and their nitro derivatives from indoor biomass-fuelled cooking in two rural areas of Thailand: a case study, Air Qual. Atmos. Hlth., 10, 747761, https://doi.org/10.1007/s11869-017-0467-y, 2017.

Özel, M. Z., Hamilton, J. F., and Lewis, A. C.: New sensitive and quantitative analysis method for organic nitrogen compounds in urban aerosol samples, Environ. Sci. Technol., 45, 1497-1505, https://doi.org/10.1021/es102528g, 2011.

Pavlovic, J. and Hopke, P. K.: Chemical nature and molecular weight distribution of the water-soluble fine and ultrafine PM fractions collected in a rural environment, Atmos. Environ., 59, 264-271, https://doi.org/10.1016/j.atmosenv.2012.04.053, 2012.

Pham, C. T., Kameda, T., Toriba, A., and Hayakawa, K.: Polycyclic aromatic hydrocarbons and nitropolycyclic aromatic hydrocarbons in particulates emitted by motorcycles, Environ. Pollut., 183, 175-183, https://doi.org/10.1016/j.envpol.2013.01.003, 2013.

Ringuet, J., Leoz-Garziandia, E., Budzinski, H., Villenave, E., and Albinet, A.: Particle size distribution of nitrated and oxygenated polycyclic aromatic hydrocarbons (NPAHs and OPAHs) on traffic and suburban sites of a European megacity: Paris (France), Atmos. Chem. Phys., 12, 8877-8887, https://doi.org/10.5194/acp12-8877-2012, 2012.

Saffari, A., Daher, N., Samara, C., Voutsa, D., Kouras, A., Manoli, E., Karagkiozidou, O., Vlachokostas, C., Moussiopoulos, N., Shafer, M. M., Schauer, J. J., and Sioutas, C.: Increased Biomass Burning Due to the Economic Crisis in Greece and Its Adverse Impact on Wintertime Air Quality in Thessaloniki, Environ. Sci. Technol., 47, 13313-13320, https://doi.org/10.1021/es403847h, 2013.

Samburova, V., Connolly, J., Gyawali, M., Yatavelli, R. L. N., Watts, A. C., Chakrabarty, R. K., Zielinska, B., Moosmüller, H., and Khlystov, A.: Polycyclic aromatic hydrocarbons in 
biomass-burning emissions and their contribution to light absorption and aerosol toxicity, Sci. Total Environ., 568, 391-401, https://doi.org/10.1016/j.scitotenv.2016.06.026, 2016.

Seki, K., Noya, Y., Mikami, Y., Taneda, S., Suzuki, A. K., Kuge, Y., and Ohkura, K.: Isolation and identification of new vasodilative substances in diesel exhaust particles, Environ. Sci. Pollut. R., 17, 717-723, https://doi.org/10.1007/s11356-009-0207-4, 2010.

Shahpoury, P., Kitanovski, Z., and Lammel, G.: Snow scavenging and phase partitioning of nitrated and oxygenated aromatic hydrocarbons in polluted and remote environments in central Europe and the European Arctic, Atmos. Chem. Phys., 18, 1349513510, https://doi.org/10.5194/acp-18-13495-2018, 2018.

Shen, G., Tao, S., Wei, S., Zhang, Y., Wang, R., Wang, B., Li, W., Shen, H., Huang, Y., Chen, Y., Chen, H., Yang, Y., Wang, W., Wang, X., Liu, W., and Simonich, S. L. M.: Emissions of parent, nitro, and oxygenated polycyclic aromatic hydrocarbons from residential wood combustion in rural China, Environ. Sci. Technol., 46, 8123-8130, https://doi.org/10.1021/es301146v, 2012.

Shen, G., Xue, M., Wei, S., Chen, Y., Wang, B., Wang, R., Lv, Y., Shen, H., Li, W., Zhang, Y., Huang, Y., Chen, H., Wei, W., Zhao, Q., Li, B., Wu, H., and Tao, S.: Emissions of parent, nitrated, and oxygenated polycyclic aromatic hydrocarbons from indoor corn straw burning in normal and controlled combustion conditions, J. Environ. Sci., 25, 2072-2080, https://doi.org/10.1016/S10010742(12)60249-6, 2013a.

Shen, G., Tao, S., Wei, S., Chen, Y., Zhang, Y., Shen, H., Huang, Y., Zhu, D., Yuan, C., Wang, H., Wang, Y., Pei, L., Liao, Y., Duan, Y., Wang, B., Wang, R., Lv, Y., Li, W., Wang, $\mathrm{X}$, and Zheng, X.: Field measurement of emission factors of PM, EC, OC, parent, nitro-, and oxy- polycyclic aromatic hydrocarbons for residential briquette, coal cake, and wood in rural Shanxi, China, Environ. Sci. Technol., 47, 2998-3005, https://doi.org/10.1021/es304599g, 2013 b.

Shen, G. F., Chen, Y. C., Du, W., Lin, N., Wang, X. L., Cheng, H. F., Liu, J. F., Xue, C. Y., Liu, G. Q., Zeng, E. Y., Xing, B. S., and Tao, S.: Exposure and size distribution of nitrated and oxygenated polycyclic aromatic hydrocarbons among the population using different household fuels, Environ. Pollut., 216, 935-942, https://doi.org/10.1016/j.envpol.2016.07.002, 2016.

Song, J. Z., Li, M. J., Jiang, B., Wei, S. Y., Fan, X. J., and Peng, P.: Molecular characterization of water-soluble Humic like Substances in smoke particles emitted from combustion of biomass materials and coal using ultrahigh-resolution electrospray ionization Fourier transform ion cyclotron resonance mass spectrometry, Environ. Sci. Technol., 52, 2575-2585, https://doi.org/10.1021/acs.est.7b06126, 2018.

Souza, K. F., Carvalho, L. R. F., Allen, A. G., and Cardoso, A. A.: Diurnal and nocturnal measurements of PAH, nitro-PAH, and oxy-PAH compounds in atmospheric particulate matter of a sugar cane burning region, Atmos. Environ., 83, 193-201, https://doi.org/10.1016/j.atmosenv.2013.11.007, 2014.

Stevanovic, S., Miljevic, B., Surawski, N. C., Fairfull-Smith, K. E., Bottle, S. E., Brown, R., and Ristovski, Z. D.: Influence of oxygenated organic aerosols (OOAs) on the oxidative potential of diesel and biodiesel particulate matter, Environ. Sci. Technol., 47, 7655-7662, https://doi.org/10.1021/es4007433, 2013.

Teich, M., van Pinxteren, D., and Herrmann, H.: Determination of nitrophenolic compounds from atmospheric particles using hollow-fiber liquid-phase microextraction and capillary electrophoresis/mass spectrometry analysis, Electrophoresis, 35, 1353-1361, https://doi.org/10.1002/elps.201300448, 2014.

Teich, M., van Pinxteren, D., Wang, M., Kecorius, S., Wang, Z., Müller, T., Močnik, G., and Herrmann, H.: Contributions of nitrated aromatic compounds to the light absorption of watersoluble and particulate brown carbon in different atmospheric environments in Germany and China, Atmos. Chem. Phys., 17, 1653-1672, https://doi.org/10.5194/acp-17-1653-2017, 2017.

Tomaz, S., Shahpoury, P., Jaffrezo, J.-L., Lammel, G., Perraudin, E., Villenave, E., and Albinet, A.: One-year study of polycyclic aromatic compounds at an urban site in Grenoble (France): seasonal variations, gas/particle partitioning and cancer risk estimation, Sci. Total Environ., 565, 1071-1083, https://doi.org/10.1016/j.scitotenv.2016.05.137, 2016.

van Pinxteren, D. and Herrmann, H.: Determination of functionalised carboxylic acids in atmospheric particles and cloud water using capillary electrophoresis/mass spectrometry, J. Chromatogr. A, 1171, 112-123, https://doi.org/10.1016/j.chroma.2007.09.021, 2007.

van Pinxteren, D., Teich, M., and Herrmann, H.: Hollow fibre liquid-phase microextraction of functionalised carboxylic acids from atmospheric particles combined with capillary electrophoresis/mass spectrometric analysis, J. Chromatogr. A, 1267, 178-188, https://doi.org/10.1016/j.chroma.2012.06.097, 2012

Velali, E., Pantazaki, A., Besis, A., Choli-Papadopoulou, T., and Samara, C.: Oxidative stress, DNA damage, and mutagenicity induced by the extractable organic matter of airborne particulates on bacterial models, Regul. Toxicol. Pharm., 104, 59-73, https://doi.org/10.1016/j.yrtph.2019.03.004, 2019.

Verma, V., Wang, Y., el Afifi, R., Fang, T., Rowland, J., Russell, A. G., and Weber, R. J.: Fractionating ambient humic-like substances (HULIS) for their reactive oxygen species activity - assessing the importance of quinones and atmospheric aging, Atmos. Environ., 120, 351-359, https://doi.org/10.1016/j.atmosenv.2015.09.010, 2015.

Vicente, E. D., Vicente, A. M., Musa Bandowe, B. A., and Alves, C. A.: Particulate phase emission of parent polycyclic aromatic hydrocarbons (PAHs) and their derivatives (alkyl-PAHs, oxygenated-PAHs, azaarenes and nitrated PAHs) from manually and automatically fired combustion appliances, Air Qual. Atmos. Heal., 9, 653-668, https://doi.org/10.1007/s11869-015-0364-1, 2016.

Vione, D., Maurino, V., and Minero, C.: Photosensitized humiclike substances (HULIS) formation processes of atmospheric significance: a review, Environ. Sci. Pollut. R., 21, 11614-11622, https://doi.org/10.1007/s11356-013-2319-0, 2014.

Voliotis, A., Prokeš, R., Lammel, G., and Samara, C.: New insights on humic-like substances associated with urban aerosols from central and southern Europe: size-resolved chemical characterization and optical properties, Atmos. Environ., 166, 286-299, https://doi.org/10.1016/j.atmosenv.2017.07.024, 2017.

Walgraeve, C., Demeestere, K., Dewulf, J., Zimmermann, R., and van Langenhove, H.: Oxygenated polycyclic aromatic hydrocarbons in atmospheric particulate matter: Molecular characterization and occurrence, Atmos. Environ., 44, 1831-1846, https://doi.org/10.1016/j.atmosenv.2009.12.004, 2010.

Wang, L., Wang, X., Gu, R., Wang, H., Yao, L., Wen, L., Zhu, F., Wang, W., Xue, L., Yang, L., Lu, K., Chen, J., Wang, T., Zhang, Y., and Wang, W.: Observations of fine particulate nitrated phe- 
nols in four sites in northern China: concentrations, source apportionment, and secondary formation, Atmos. Chem. Phys., 18, 4349-4359, https://doi.org/10.5194/acp-18-4349-2018, 2018.

Wang, X., Gu, R., Wang, L., Xu, W., Zhang, Y., Chen, B., Li, W., Xue, L., Chen, J., and Wang, W.: Emissions of fine particulate nitrate phenols from the burning of five common types of biomass, Environ. Pollut., 230, 405-412, https://doi.org/10.1016/j.envpol.2017.06.072, 2017.

Wang, Y., Hu, M., Wang, Y., Zheng, J., Shang, D., Yang, Y., Liu, Y., Li, X., Tang, R., Zhu, W., Du, Z., Wu, Y., Guo, S., Wu, Z., Lou, S., Hallquist, M., and Yu, J. Z.: The formation of nitro-aromatic compounds under high $\mathrm{NO}_{x}$ and anthropogenic VOC conditions in urban Beijing, China, Atmos. Chem. Phys., 19, 7649-7665, https://doi.org/10.5194/acp-19-7649-2019, 2019.

Wesp, H. F., Tang, X., and Edenharder, R.: The influence of automobile exhausts on mutagenicity of soils: contamination with, fractionation, separation, and preliminary identification of mutagens in the Salmonella/reversion assay and effects of solvent fractions on the sister-chromatid exchanges in human lymphocyte cultures and in the in vivo mouse bone marrow micronucleus assay, Mutation Res., 472, 1-21, https://doi.org/10.1016/S13835718(00)00088-7, 2000.

Winkler, P. and Junge, C. E.: Growth of atmospheric particles as a function of relative humidity, J. Rech. Atmos., 72, 617-638, 1972.

Xie, M. J., Chen, X., Hays, M. D., Lewandowski, M., Offenberg, J., Kleindienst, T. E., and Holder, A. L.: Light absorption of secondary organic aerosol: composition and contribution of nitroaromatic compounds, Environ. Sci. Technol., 51, 1160711616, https://doi.org/10.1021/acs.est.7b03263, 2017.
Zhang, X., Hecobian, A., Zheng, M., Frank, N. H., and Weber, R. J.: Biomass burning impact on $\mathrm{PM}_{2.5}$ over the southeastern US during 2007: integrating chemically speciated FRM filter measurements, MODIS fire counts and PMF analysis, Atmos. Chem. Phys., 10, 6839-6853, https://doi.org/10.5194/acp10-6839-2010, 2010.

Zheng, G., He, K., Duan, F., Cheng, Y., and Ma, Y.: Measurement of humic-like substances in aerosols: a review, Environ. Pollut., 181, 301-314, https://doi.org/10.1016/j.envpol.2013.05.055, 2013.

Zhuo, S., Du, W., Shen, G., Li, B., Liu, J., Cheng, H., Xing, B., and Tao, S.: Estimating relative contributions of primary and secondary sources of ambient nitrated and oxygenated polycyclic aromatic hydrocarbons, Atmos. Environ., 159, 126-134, https://doi.org/10.1016/j.atmosenv.2017.04.003, 2017.

Zielinska, B., Sagebiel, J., Arnott, W. P., Rogers, C. F., Kelly, K. E., Wagner, D. A., Lighty, J. S., Sarofim, A. F., and Palmer, G.: Phase and size distribution of polycyclic aromatic hydrocarbons in diesel and gasoline vehicle emissions, Environ. Sci. Technol., 38, 2557-2567, https://doi.org/10.1021/es030518d, 2004. 